\title{
Evaluation of the offline-coupled GFSv15-FV3-CMAQv5.0.2 in support of the next-generation National Air Quality Forecast Capability over the contiguous United States
}

\author{
Xiaoyang Chen ${ }^{1}$, Yang Zhang ${ }^{1}$, Kai Wang ${ }^{1}$, Daniel Tong ${ }^{2,6}$, Pius Lee ${ }^{4,3}$, Youhua Tang ${ }^{3,4}$, Jianping Huang ${ }^{5,6}$, \\ Patrick C. Campbell ${ }^{3,4}$, Jeff Mcqueen ${ }^{5}$, Havala O. T. Pye ${ }^{7}$, Benjamin N. Murphy ${ }^{7}$, and Daiwen Kang ${ }^{7}$ \\ ${ }^{1}$ Department of Civil and Environmental Engineering, Northeastern University, Boston, MA 02115, USA \\ ${ }^{2}$ Department of Atmospheric, Oceanic and Earth Sciences, George Mason University, Fairfax, VA 22030, USA \\ ${ }^{3}$ Center for Spatial Information Science and System, George Mason University, Fairfax, VA 22030, USA \\ ${ }^{4}$ Air Resources Laboratory, National Oceanic and Atmospheric Administration, College Park, MD 20740, USA \\ ${ }^{5}$ National Oceanic and Atmospheric Administration/National Centers for Environmental Prediction/Environmental Modeling \\ Center, College Park, MD 20740, USA \\ ${ }^{6}$ IM Systems Group, Rockville, MD 20852, USA \\ ${ }^{7}$ Office of Research and Development, U.S. Environmental Protection Agency, Research Triangle Park, NC 27711, USA
}

Correspondence: Yang Zhang (ya.zhang@ northeastern.edu)

Received: 11 August 2020 - Discussion started: 2 September 2020

Revised: 19 January 2021 - Accepted: 7 February 2021 - Published: 29 June 2021

\begin{abstract}
As a candidate for the next-generation National Air Quality Forecast Capability (NAQFC), the meteorological forecast from the Global Forecast System with the new Finite Volume Cube-Sphere dynamical core (GFS-FV3) will be applied to drive the chemical evolution of gases and particles described by the Community Multiscale Air Quality modeling system. CMAQv5.0.2, a historical version of CMAQ, has been coupled with the North American Mesoscale Forecast System (NAM) model in the current operational NAQFC. An experimental version of the NAQFC based on the offline-coupled GFS-FV3 version 15 with CMAQv5.0.2 modeling system (GFSv15-CMAQv5.0.2) has been developed by the National Oceanic and Atmospheric Administration (NOAA) to provide real-time air quality forecasts over the contiguous United States (CONUS) since 2018. In this work, comprehensive region-specific, timespecific, and categorical evaluations are conducted for meteorological and chemical forecasts from the offline-coupled GFSv15-CMAQv5.0.2 for the year 2019. The forecast system shows good overall performance in forecasting meteorological variables with the annual mean biases of $-0.2{ }^{\circ} \mathrm{C}$ for temperature at $2 \mathrm{~m}, 0.4 \%$ for relative humidity at $2 \mathrm{~m}$, and $0.4 \mathrm{~m} \mathrm{~s}^{-1}$ for wind speed at $10 \mathrm{~m}$ compared to the ME-
\end{abstract}

Teorological Aerodrome Reports (METAR) dataset. Larger biases occur in seasonal and monthly mean forecasts, particularly in spring. Although the monthly accumulated precipitation forecasts show generally consistent spatial distributions with those from the remote-sensing and ensemble datasets, moderate-to-large biases exist in hourly precipitation forecasts compared to the Clean Air Status and Trends Network (CASTNET) and METAR. While the forecast system performs well in forecasting ozone $\left(\mathrm{O}_{3}\right)$ throughout the year and fine particles with a diameter of $2.5 \mu \mathrm{m}$ or less $\left(\mathrm{PM}_{2.5}\right)$ for warm months (May-September), it significantly overpredicts annual mean concentrations of $\mathrm{PM}_{2.5}$. This is due mainly to the high predicted concentrations of fine fugitive and coarse-mode particle components. Underpredictions in the southeastern US and California during summer are attributed to missing sources and mechanisms of secondary organic aerosol formation from biogenic volatile organic compounds (VOCs) and semivolatile or intermediate-volatility organic compounds. This work demonstrates the ability of FV3-based GFS in driving the air quality forecasting. It identifies possible underlying causes for systematic regionand time-specific model biases, which will provide a sci- 
entific basis for further development of the next-generation NAQFC.

\section{Introduction}

Three-dimensional air quality models (3-D AQMs) have been widely applied in real-time air quality forecasting (RTAQF) since the 1990s in the US (Stein et al., 2000; McHenry et al., 2004; Zhang et al., 2012a). The developments and applications of the national air quality forecasting systems based on 3-D AQMs were conducted in the 2000s (Kang et al., 2005; Otte et al., 2005; McKeen et al., 2005, 2007, 2009). Since then, improvements and significant progress have been achieved in RT-AQF through the further development of AQMs and the use of advanced techniques. For example, more air pollutants in the products, more detailed gas-phase chemical mechanisms and aerosol chemistry, and the implementation of chemical data assimilation were available (Zhang et al., 2012b; Lee et al., 2017). Various AQMs, coupled with meteorological models in either an online or offline manner, were developed and applied in RT-AQF (e.g., Chuang et al., 2011; Lee et al., 2011; Žabkar et al., 2015; Ryan, 2016). The early version of the National Air Quality Forecast Capability (NAQFC) was jointly developed by the US National Oceanic and Atmospheric Administration (NOAA) and the U.S. Environmental Protection Agency (EPA) to provide forecasts of ozone $\left(\mathrm{O}_{3}\right)$ over the northeastern US (Eder et al., 2006). Since the first operational version over the contiguous United States (CONUS) (Eder et al., 2009), the NAQFC has been continuously updated and developed to provide more forecasting products (including $\mathrm{O}_{3}$, smoke, dust, and particulate matter with a diameter of $2.5 \mu \mathrm{m}$ or less $\left(\mathrm{PM}_{2.5}\right)$ ) with increasing accuracy (Mathur et al., 2008; Stajner et al., 2011; Lee et al., 2017).

The forecast skill of a historical NAQFC, which was based on the North American Mesoscale Forecast System (NAM) model (Black, 1994) and the Community Multiscale Air Quality Modeling System version 4.6 (CMAQv4.6), over CONUS during the year 2008 was evaluated by Kang et al. (2010a) for operational $\mathrm{O}_{3}$ and experimental $\mathrm{PM}_{2.5}$ products. Overall, maximum $8 \mathrm{~h} \mathrm{O}_{3}$ was slightly overpredicted over the CONUS during the summer, with a mean bias (MB), normalized mean bias (NMB), and correlation coefficient (Corr) of $3.2 \mathrm{ppb}, 6.8 \%$, and 0.65 , respectively. The performance of predicted daily mean $\mathrm{PM}_{2.5}$ varied: there was an underprediction during the warm season and an overprediction in the cool season. The MBs and NMBs during warm/cool seasons were $-2.3 / 4.5 \mu \mathrm{g} \mathrm{m}^{-3}$ and $-19.6 \% / 45.1 \%$, respectively. The current version of the US NOAA's operational NAQFC has provided the air quality forecast to the public for $\mathrm{O}_{3}$ and $\mathrm{PM}_{2.5}$ at a horizontal grid resolution of $12 \mathrm{~km}$ over CONUS since 2015 . It is currently based on the CMAQv5.0.2 (released May 2014) (U.S.
EPA, 2014) coupled offline with the NAM model. Daily mean $\mathrm{PM}_{2.5}$ was underpredicted during warm months (May and July 2014) and overpredicted during a cool month (January 2015) over CONUS (Lee et al., 2017).

Efforts have been made to reduce the seasonal and regionspecific biases in the historical and current NAQFC. Development and implementation of an analog ensemble bias correction approach was applied to the operational NAQFC to improve forecast performance in $\mathrm{PM}_{2.5}$ predictions (Huang et al., 2017). Kang et al. (2008, 2010b) investigated the Kalman filter (KF) bias-adjustment technique for operational use in the NAQFC system. The KF bias-adjusted forecasts showed significant improvement in both $\mathrm{O}_{3}$ and $\mathrm{PM}_{2.5}$ for discrete and categorical evaluations. However, limitations in the underlying models and the bias correction or adjustment approaches need further improvement. Characterizing the current NAQFC forecasting skill and identifying the underlying causes for region- and time-specific biases can result in further development of the NAQFC system and improved pollutant predictions.

As the NOAA Environmental Modeling Center (EMC) has transitioned to devote its full resources to the development of an ensemble model based on the Finite Volume Cube-Sphere Dynamical Core (FV3), NAM has been no longer updated since March 2017. The FV3 dynamic core will eventually replace all current NOAA National Centers for Environmental Prediction (NCEP) mesoscale models used for forecasting. The FV3 dynamical core was implemented in the operational Global Forecast System as version 15 (GFSv15) in July 2019.

The NOAA National Weather Service (NWS) is currently coordinating an effort to inline a regional-scale meteorological model based on the same FV3 dynamic core as that in GFSv15 to be coupled with an atmospheric chemistry model partially based on CMAQ. The inline system is expected to be the next generation of NAQFC and to be implemented a few years into the future. An interim system, offline coupling the recent CMAQ with FV3-based GFS is regarded as a candidate NAQFC to replace the current NAM-CMAQ system before the inline system is applied in operational air quality forecasting. To support this new development of the interim NAQFC, a prototype of the offline-coupled GFSv15 with CMAQv5.0.2 (GFSv15-CMAQv5.0.2) has been developed and applied by the NOAA for RT-AQF over CONUS since 2018 (Huang et al., 2018, 2019). In this work, the meteorological and air quality forecasts from the offlinecoupled GFSv15-CMAQv5.0.2 system are comprehensively evaluated for the year of 2019. The main objectives of this work are to (1) evaluate the forecast skills of the experimental prototype of the GFSv15-CMAQv5.0.2 system, (2) identify the major model biases, in particular, systematic biases and persistent region- and time-specific biases in major species, and (3) investigate underlying causes for the biases to provide a scientific basis for improving the model representations of chemical processes and developing science- 
based bias correction methods for $\mathrm{O}_{3}$ and $\mathrm{PM}_{2.5}$ forecasts. This work will support NAQFC's further development and improvement through enhancing its forecasting abilities and generating a benchmark for the interim NAQFC that is being developed by NOAA based on the offline-coupled GFSFV3 v16 with CMAQv5.3 (NACC-CMAQ) (Campbell et al., 2020). Eventually, the latest version of CMAQ (version 5.3), which has updates in gas-phase chemistry (Yarwood et al., 2010; Emery et al., 2015; Luecken et al., 2019), lightning nitric oxide (LNO) production schemes (Kang et al., 2019a, b), and secondary aerosol formation (in particular, secondary organic aerosol) (e.g., Pye et al., 2013, 2017; Murphy et al., 2017) among other things, will be coupled with GFS-FV3 v16 and be implemented in the interim operational NAQFC.

\section{Model system and evaluation protocols}

\subsection{Description and configuration of offline-coupled GFSv15-CMAQv5.0.2}

FV3 is a dynamical core for atmospheric numerical models developed by the Geophysical Fluid Dynamics Laboratory (GFDL) (Putman and Lin, 2007). It is a modern and extended version of the original FV core with a cubed-sphere grid design and more computationally efficient solvers. It was selected for implementation into the GFS as the next generation dynamical core in 2016 (C. Zhang et al., 2019). The GFS-FV3 v15 (GFSv15) has been operational since June 2019. The GFSv15 uses the Rapid Radiative Transfer Method for General Circulation Models (RRTMG) scheme for shortwave or longwave radiation (Mlawer et al., 1997; Iacono et al., 2000; Clough et al., 2005), the Hybrid eddy-diffusivity mass-flux (EDMF) scheme for the planetary boundary layer (PBL) (National Centers for Environmental Prediction, 2019a), the Noah Land Surface Model (LSM) scheme for the land surface option (Chen et al., 1997), the simplified Arakawa-Schubert (SAS) deep convection for cumulus parameterization (Arakawa and Schubert, 1974; Grell, 1993), and a more advanced GFDL microphysics scheme for microphysics (National Centers for Environmental Prediction, 2019b). An interface preprocessor has been developed by NOAA to interpolate data, transfer coordinates, and convert the GFSv15 outputs into the data format required by CMAQv5.0.2 (Huang et al., 2018, 2019). The original outputs from GFSv15, which have a horizontal grid with $13 \mathrm{~km}$ resolution and a Lagrangian vertical coordinate with 64 layers in I/O format for the NCEP models using the NOAA Environmental Modeling System (NEMSIO), are processed to Lambert conformal conic projection by PREMAQ, a preprocessor, to recast the meteorological fields for CMAQ into an Arakawa C-staggering grid (Arakawa and Lamb, 1977) with a $12 \mathrm{~km}$ horizontal resolution and 35 vertical layers (Table 1). The first $72 \mathrm{~h}$ in 12:00 UTC forecast cycles from GFSv15 are used to drive the air quality forecast by the offline-coupled GFSv15-CMAQv5.0.2 system.

CMAQ has been continuously developed by the U.S. EPA since the 1990s (Byun and Schere, 2006) and has been significantly updated in many atmospheric processes since then. Chemical boundary conditions for the GFSv15CMAQv5.0.2 system are mainly from the global 3-D model of atmospheric chemistry driven by meteorological input from the Goddard Earth Observing System (GEOS-Chem). The lateral boundary condition for dust is from the outputs of the NOAA Environmental Modeling System GFS aerosol component (NGAC) (Lu et al., 2016). The anthropogenic emissions from area, mobile, and point sources in the National Emissions Inventory of the year 2014 version 2 (NEI 2014v2) are processed by the Sparse Matrix Operator Kernel Emissions (SMOKE) modeling system. The onroad mobile sources include all emissions from motor vehicles that operate on roadways, such as passenger cars, motorcycles, minivans, sport-utility vehicles, light-duty trucks, heavy-duty trucks, and buses. On-road mobile source emissions were processed using emission factors output from the Motor Vehicle Emissions Simulator (MOVES). SMOKE uses a combination of vehicle activity data, emission factors from MOVES, meteorology data, and temporal allocation information to estimate hourly, gridded on-road emissions. The non-road, agriculture, anthropogenic fugitive dust, non-elevated oil-gas, residential wood combustion, and other sectors are included in the area sources. The sectors of airports, commercial marine vessel (CMV), electric generating units (pt_egu), point sources related to oil and gas production (pt_oilgas), point sources that are not electric generating units (EGUs) nor related to oil and gas (pt_nonipm), and point sources outside the US (pt_other) are included in the point sources. The sulfur dioxide $\left(\mathrm{SO}_{2}\right)$ and nitrogen oxide $\left(\mathrm{NO}_{x}\right)$ from point sources in NEI 2005 are projected to the year 2019 following the methods used in Tang et al., (2015, 2017). The biomass burning emission inventory from the Blended Global Biomass Burning Emissions Product system (GBBEPx) (X. Zhang et al., 2019) is implemented for the forecast of forest fires. The GBBEPx fire emission is treated as one type of point source. Its heat flux is derived from satellite-retrieved fire radiative power (FRP) to drive fire plume rise. The GBBEPx is a near-real-time fire dataset. The fire emission implemented in the current forecast cycle comes from the historical fire observation, typically $1-2 \mathrm{~d}$ behind. In this system, we use land use information to classify fires as forest fire and other burning such as agriculture burning. We assume that only forest fire can last longer than $24 \mathrm{~h}$. We assume that the forest fire emission will continue on day 2 and beyond. Other types of fires will be dropped. The plume rise of the point source will be driven by the meteorology and allocated to the 35 elevated layers in the GFSv15-CMAQv5.0.2 system by the PREMAQ preprocessing system. Biogenic emissions are calculated inline by the Biogenic Emission Inventory System (BEIS) version 
Table 1. Configuration of GFSv15-CMAQv5.0.2 system.

\begin{tabular}{ll}
\hline Attribute & Model configuration \\
\hline Forecast period & January-December 2019 \\
\hline Domain & Contiguous US \\
\hline Resolution & Horizontal: 12 km (442 × 265); vertical: 35 layers \\
\hline Physical Options & The Rapid Radiative Transfer Method for GCMs \\
\hline Shortwave or longwave radiation & Hybrid eddy-diffusivity mass-flux (EDMF) PBL \\
\hline Planetary boundary layer (PBL) & Noah Land Surface Model (LSM) \\
\hline Land surface & A more advanced GFDL microphysics scheme \\
\hline Microphysics & The simplified Arakawa-Schubert (SAS) deep convection \\
\hline Cumulus & $\begin{array}{l}\text { The Carbon Bond mechanism version 5 with active chlorine chemistry and up- } \\
\text { dated toluene mechanism (CB05tucl) (Yarwood et al., 2005; Sarwar et al., 2012) }\end{array}$ \\
\hline Chemical options & AQCHEM (Sarwar et al., 2011) \\
\hline Photolysis & \begin{tabular}{l} 
AERO6 with non-volatile POA (Carlton et al., 2010; Simon and Bhave, 2012; \\
\hline Gas-phase chemistry
\end{tabular} \\
\hline Aqueous-phase chemistry & Inline method (Binkowski et al., 2007) \\
\hline Aerosol module & Appel al., \\
\hline
\end{tabular}

3.14 (Schwede et al., 2005). Sea-salt emission is parameterized within CMAQv5.0.2. While the deposition velocities are calculated inline, the fertilizer ammonia bidirectional flux for inline emissions and deposition velocities is turned off. Detailed configurations of photolysis, gas-phase chemistry, aqueous chemistry, and aerosol chemistry for CMAQv5.0.2 are listed in Table 1.

\subsection{Datasets and evaluation protocols}

A comprehensive evaluation of the GFSv15-CMAQv5.0.2 forecasting system is conducted for both meteorological and chemical variables for the year 2019, including discrete, categorical, and region-specific evaluations. The products in the first $24 \mathrm{~h}$ of each $72 \mathrm{~h}$ forecast cycle are extracted and combined as a continuous, annual forecast. The evaluation of meteorological variables is carried out for those results from PREMAQ in the GFSv15-CMAQv5.0.2 system. Detailed information for datasets used in this study is listed in Table S1 in the Supplement. Observed hourly temperature at $2 \mathrm{~m}(T 2)$, relative humidity at $2 \mathrm{~m}(\mathrm{RH} 2)$, precipitation (Precip), wind direction at $10 \mathrm{~m}$ (WD10), and wind speed at $10 \mathrm{~m}$ (WS10) are obtained from the Clean Air Status and Trends Network (CASTNET) and the METeorological Aerodrome Reports (METAR) datasets. The majority of CASTNET sites are suburban and rural sites. Approximately 1900 METAR sites over CONUS are used in this study (Fig. S1 in the Supplement). For the evaluation of precipitation, a threshold of $\geq 0.1 \mathrm{~mm} \mathrm{~h}^{-1}$ is used for valid records because CASTNET and METAR have different definitions of $0.0 \mathrm{~mm} \mathrm{~h}^{-1}$ values. In CASTNET, the records without any precipitation are given as $0.0 \mathrm{~mm} \mathrm{~h}^{-1}$, the same as those records with negligible precipitation. However, in METAR, the records without any precipitation are left blank, the same as an invalid record. The negligible precipitation is recorded as $0.0 \mathrm{~mm} \mathrm{~h}^{-1}$.

The air quality forecasting products that are evaluated include hourly $\mathrm{O}_{3}$, hourly $\mathrm{PM}_{2.5}$, maximum daily $8 \mathrm{~h}$ average $\mathrm{O}_{3}\left(\mathrm{MDA} 8 \mathrm{O}_{3}\right)$, and daily average $\mathrm{PM}_{2.5}(24 \mathrm{~h}$ average $\mathrm{PM}_{2.5}$ ) for chemical forecast. The AIRNow dataset is used for observed hourly $\mathrm{O}_{3}$ and $\mathrm{PM}_{2.5}$. We utilize the quality assurance/quality control (QA/QC) information from the AIRNow dataset to filter the invalid records. Remote-sensing data from the Global Precipitation Climatology Project (GPCP) and the Climatology-Calibrated Precipitation Analysis (CCPA) (Hou et al., 2014; Zhu and Luo, 2015) datasets are also used for the evaluation of precipitation. GPCP is a global precipitation dataset with a spatial resolution of $0.25^{\circ}$ and a monthly temporal resolution. The CCPA uses linear regression and downscaling techniques to generate an analysis product of precipitation from two datasets: the NCEP Climate Prediction Center Unified Global Daily Gauge Analysis and the NCEP EMC Stage IV multi-sensor quantitative precipitation estimations (QPEs). The CCPA product with a spatial resolution in $0.125^{\circ}$ and temporal resolution of an hour is used in this study. Satellite-based aerosol optical depth (AOD) at $550 \mathrm{~nm}$ from the Moderate Resolution Imaging 
Spectroradiometer (MODIS) Terra platform (Levy and Hsu, 2015 ) is used for the evaluation of monthly AOD. The statistical measures such as mean bias, the root mean square error (RMSE), the normalized mean bias, the normalized mean error (NME), and the correlation coefficient are used; more details about evaluation protocols are found in Zhang et al. (2009, 2016). The Taylor diagram (Taylor, 2001), which includes the correlations, NMBs, and the normalized standard deviations (NSDs), is used to present the overall performance (Wang et al., 2015). The NMBs $\leq 15 \%$ and NMEs $\leq 30 \%$ by Zhang et al. (2006) and NMBs $(\leq 15 \%$ and $\leq 30 \%)$, NMEs $(\leq 25 \%$ and $\leq 50 \%)$, and Corr $(>0.5$ and $>0.4$ ) for MDA8 $\mathrm{O}_{3}$ and $24 \mathrm{~h} \mathrm{PM}_{2.5}$, respectively, by Emery et al. (2017) are regarded as performance criteria. Monthly, seasonal, and annual statistics and analysis are included. Seasonal analysis for $\mathrm{O}_{3}$ is separated into an $\mathrm{O}_{3}$ season (May-September) and a non- $\mathrm{O}_{3}$ season (January-April and October-December). Analysis for 10 CONUS regions, defined by the U.S. EPA (http://www.epa.gov/aboutepa, last access: 10 August 2020), is included and listed in Fig. S1c in the Supplement.

The metrics of false alarm ratio (FAR) and the hit rate $(H)$ are used (Kang et al., 2005; Barnes et al., 2009) for categorical evaluation. Observed and forecasted MDA8 $\mathrm{O}_{3}$ and $24 \mathrm{~h}$ average $\mathrm{PM}_{2.5}$ values are divided into four classes based on whether the predicted and/or observed data fall above or below the air quality index (AQI) thresholds: (a) observed values $\leq$ thresholds and predicted values $>$ thresholds, (b) observed and predicted values $>$ thresholds, (c) observed and predicted values $\leq$ thresholds, and (d) observed values $>$ thresholds and predicted values $\leq$ thresholds. The FAR and $H$ are defined in Eqs. (1) and (2):

$$
\begin{aligned}
& \mathrm{FAR}=\frac{a}{a+b} \times 100 \%, \\
& H=\frac{b}{b+d} \times 100 \% .
\end{aligned}
$$

\section{Evaluation of model forecast skills}

\subsection{Evaluation of meteorological forecasts}

Discrete performance evaluation is conducted for postprocessed meteorological fields from the GFSv15-CMAQv5.0.2 system (Table 2). The GFSv15 can predict the boundary layer meteorological variables well. It has overall cold biases and wet biases for annual $T 2$ and RH2 in 2019, respectively. It also overpredicts WS10, and underpredicts hourly precipitation. Despite the CASTNET siting being slightly different from that of METAR, the annual and most of the seasonal performance for the model shows a similar pattern in terms of bias for both the CASTNET and METAR networks. The mean biases of $T 2$ are mostly within $\pm 0.5^{\circ} \mathrm{C}$ except those in February and March compared to CASTNET (Table S2 in the Supplement). Underprediction is generally larger com- pared to CASTNET than METAR. For a spatial distribution of MB for seasonal $T 2$ compared to METAR (Fig. S2 in the Supplement), cold biases are mainly found in the Midwest and western US where most of the CASTNET sites are located. GFSv15 usually underpredicts $T 2$ on the west coast, the mountain states, and the Midwest. Overpredictions of $T 2$ in the states of Kansas, Oklahoma, the areas near the east coast, and the Gulf Coast offset some underpredictions, resulting in smaller mean biases but a similar RMSE for the model compared to METAR as opposed to that compared to CASTNET. The difference between observed $T 2$ from the two datasets is larger in cooler months than warmer months. The largest underpredictions occur in the spring (March, April, May - MAM) season. In general, GFSv15 underpredicts $T 2$ for both CASTNET and METAR, consistent with cold biases found in other studies using GFSv15 (e.g., Yang, 2019). Such underpredictions will affect chemical forecasts, especially the forecast of $\mathrm{O}_{3}$. Consistent with the overall underpredictions of $T 2$, GFSv15 overpredicts RH2 in general. The largest overprediction is found in spring (MBs of $3.4 \%$ and $2.7 \%$ with CASTNET and METAR, respectively), corresponding to the largest underprediction of $T 2$ in spring (MBs of -0.5 and $-0.4{ }^{\circ} \mathrm{C}$ with CASTNET and METAR, respectively). GFSv15 shows moderately good performance when predicting wind. The annual MB and NMB of WS10 compared to METAR are $0.4 \mathrm{~m} \mathrm{~s}^{-1}$ and $10.7 \%$, respectively. A larger overprediction of WS10 is found with CASTNET than with other datasets (Zhang et al., 2016). GFSv15-CMAQv5.0.2 also gives higher overpredictions for CASTNET compared to METAR. The largest biases in wind speed are found in summer. GFSv15-CMAQv5.0.2 gives the largest cold biases and wet biases in spring, indicating the necessity of improving model performance in such seasons in future GFS-FV3 development.

By adopting the threshold of $\geq 0.1 \mathrm{mmh}^{-1}$, performance compared to the CASTNET and METAR shows similar results: a large underprediction in hourly precipitation. Predicted monthly accumulated precipitation shows consistency in spatial distribution with observations from CCPA and GPCP (Fig. S3 in the Supplement). The high precipitation in the southeast is captured well in spring, while the high precipitation in the Midwest and south is captured well in other seasons. It indicates that GFSv15-CMAQv5.0.2 has good performance in capturing the spatial distributions of accumulated precipitation but has poor performance in predicting hourly precipitation. The precipitation from the original FV3 outputs is recorded as $6 \mathrm{~h}$ accumulated precipitation. Artificial errors were introduced to the forecast by an issue in precipitation preprocessing during the early stage of the development of the GFSv15-CMAQv5.0.2 system. The precipitation at the first hour of the $6 \mathrm{~h}$ cycle would be dropped occasionally. We corrected this issue and the hourly precipitation still shows a large underprediction compared to surface monitoring networks (Fig. S4 in the Supplement). It indicates the difficulty for the forecast system in capturing the temporal 


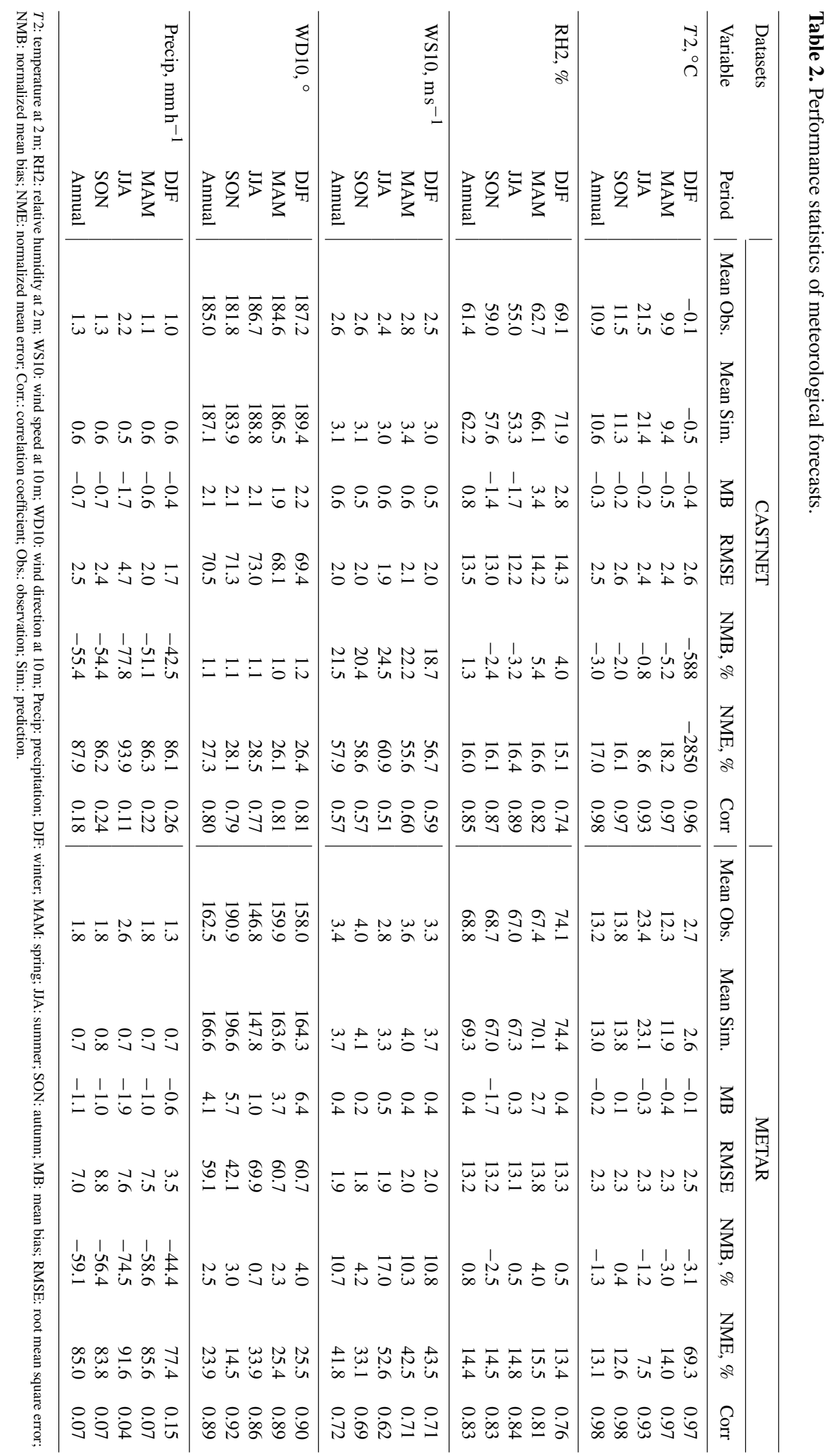




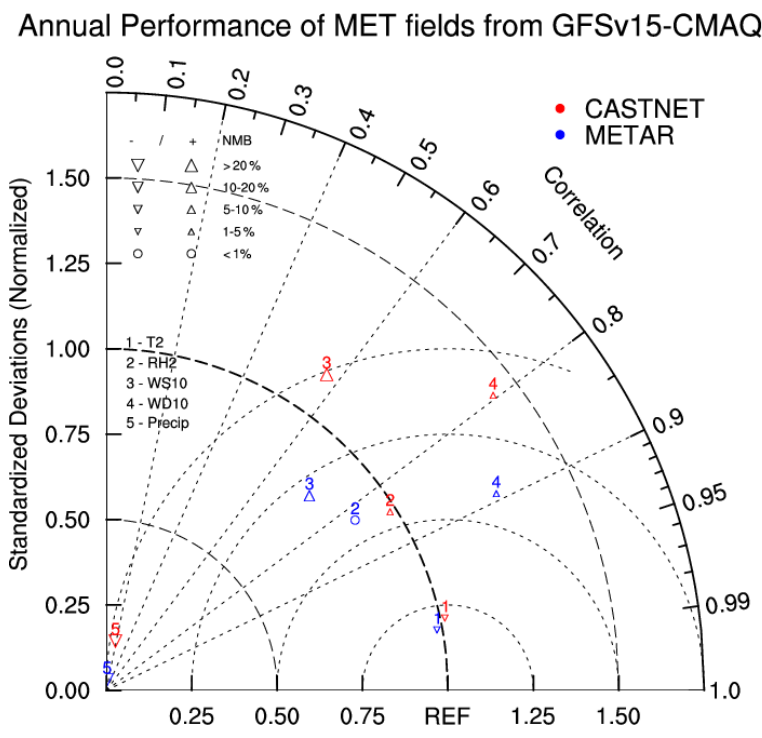

Figure 1. Taylor diagram (Taylor, 2001) with normalized standardized deviations (NSDs), Corr, and NMB for meteorological variables (T2, RH2, WS10, WD10, and Precip) compared to the CASTNET and METAR datasets. The REF marker at the $x$ axis represents the desired performance. The closer each variable is to the REF marker, the better a performance the forecast system has for that variable.

precipitation, especially during summer. During the summer season, the discrepancy in capturing the short-term heavy rainfall worsens the model performance in predicting hourly precipitation. Besides, we use the threshold of $0.1 \mathrm{~mm} \mathrm{~h}^{-1}$ to filter the valid records. If the model predicts precipitation that did not occur, the record will be excluded from the statistics calculation. However, all the predicted precipitation is counted in the spatial evaluation against the ensemble datasets of GPCP and CCPA. Therefore, the spatial performance of monthly accumulated precipitation shows better agreement than its of hourly statistics.

An overall comparison of performance with the CASTNET and METAR datasets is performed using a Taylor diagram (Fig. 1). The NSDs, Corrs, and NMBs are considered. The NSDs are ratios of the variance of predicted values to the variance of observed values, following the equations by Wang et al. (2015). The NSDs represent the amplitude of variability. With the NSDs closer to 1 , the predicted values have closer variance than the observed values. Consistent with other analysis in this section, larger biases and lower correlation in model wind speed and wind direction are found for CASTNET compared to METAR. The amplitude of variability of WS10 compared to CASTNET is overpredicted (with the NSD larger than 1), while it is underpredicted compared to METAR. Because of the postprocessing smearing of hourly precipitation, the variance of predicted precipitation is smaller than the observed one, leading to very small NSDs for precipitation. The location of the $T 2$ and
RH2 points near the REF marker in the Taylor diagram indicates that the GFSv15-CMAQv5.0.2 captures the magnitude and variability of these variables well.

\subsection{Overall performance of chemical forecast over the CONUS}

The performance of chemical forecasts (i.e., $\mathrm{O}_{3}$ and $\mathrm{PM}_{2.5}$ ) is evaluated on monthly, seasonal, and annual timescales for the studied period of 2019. The performance of the MDA8 $\mathrm{O}_{3}$ and the $24 \mathrm{~h}$ average $\mathrm{PM}_{2.5}\left(24 \mathrm{~h}\right.$ average $\left.\mathrm{PM}_{2.5}\right)$ is regarded as the primary objective. Categorical performance evaluations for MDA8 $\mathrm{O}_{3}$ and $24 \mathrm{~h}$ average $\mathrm{PM}_{2.5}$ are also conducted. Table 3 shows the discrete statistics of predicted MDA8 $\mathrm{O}_{3}$ and $24 \mathrm{~h}$ average $\mathrm{PM}_{2.5}$ compared to AIRNow.

The GFSv15-CMAQv5.0.2 has good performance for MDA8 $\mathrm{O}_{3}$ on a seasonal and annual basis with MBs $\leq$ $\pm 1.0 \mathrm{ppb}, \mathrm{NMB} \leq 2.5 \%$, and $\mathrm{NME} \leq 20 \%$. The monthly NMBs/NMEs are within $\pm 15 \% / 25 \%$, respectively. Slight overpredictions and underpredictions are found in both seasons with MB of 1.0 and $-0.2 \mathrm{ppb}$. The largest underprediction is found in spring months, especially in March. The underprediction of MDA8 $\mathrm{O}_{3}$ in spring months is consistent with the largest underprediction of $T 2$ in spring. It indicates biases in predicted $T 2$ could be one of the reasons for the corresponding biases in $\mathrm{O}_{3}$ prediction. Predicted MDA8 $\mathrm{O}_{3}$ is lower than observed values in major parts of the Midwest and western regions during the $\mathrm{O}_{3}$ season (Fig. 2), which is consistent with an underprediction of $T 2$ in summer. But GFSv15-CMAQv5.0.2 gives very high $\mathrm{O}_{3}$ in the southeastern US, especially in areas near the Gulf Coast. Such overpredictions compensate for moderate underpredictions in the Midwest and west, causing an overall overprediction in the overall CONUS. In the non- $\mathrm{O}_{3}$ season, GFSv15CMAQv5.0.2 can forecast the spatial variations of MDA8 $\mathrm{O}_{3}$ well with overall underpredictions in the northeast.

Unlike the good performance for $\mathrm{O}_{3}$, GFSv15CMAQv5.0.2 gives significant overpredictions for $24 \mathrm{~h}$ average $\mathrm{PM}_{2.5}$ with annual $\mathrm{MB}, \mathrm{NMB}$, and $\mathrm{NME}$ of $2.2 \mu \mathrm{g} \mathrm{m}^{-3}, 29.0 \%$, and $65.3 \%$, respectively (Table 3 ). The MBs and NMBs range from -0.2 to $5.0 \mu \mathrm{g} \mathrm{m}^{-3}$ and $-2.6 \%$ to $59.7 \%$ across the four seasons. With the exception of California and the southeast, predicted $24 \mathrm{~h}$ average $\mathrm{PM}_{2.5}$ shows overprediction during most of the year in spring, autumn, and winter (Fig. 3). Moderate underpredictions of $\mathrm{PM}_{2.5}$ are found in California during spring, autumn, and summer and are found in the southeast during summer. Using the historical emission inventories from NEI 2005 and NEI 2014 instead of the latest version of NEI 2017 is one of the reasons for the overpredictions of $\mathrm{PM}_{2.5}$ concentrations in 2019. The significant overprediction mainly occurs in the northern regions during cooler months, indicating it is underlaid by systematic biases. The annual emission of primary $\mathrm{PM}_{2.5}$ and coarse-mode $\mathrm{PM}$ (PMC) are shown in Fig. S5 in the Supplement. As an important surrogate for the 


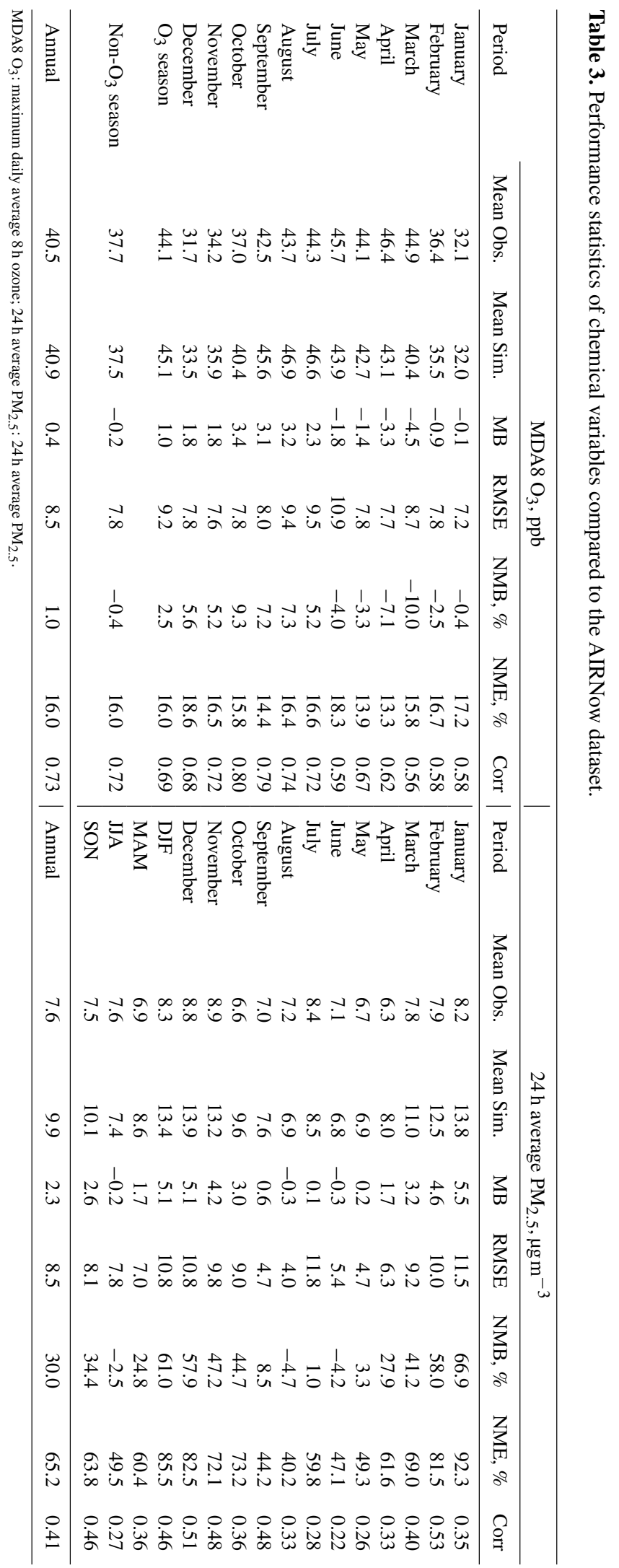



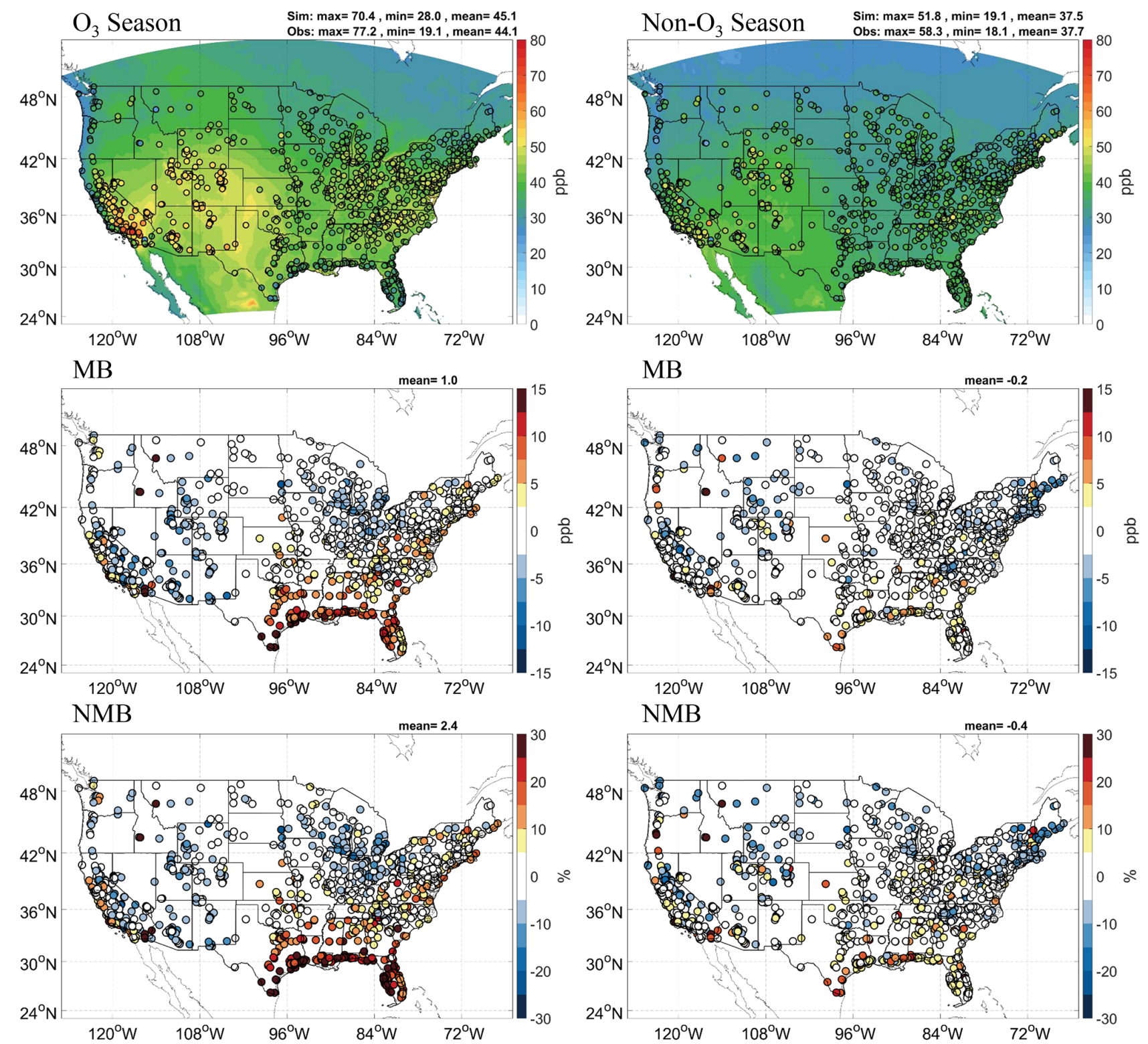

Figure 2. Spatial distribution of forecasted MDA8, MB, and NMB during the $\mathrm{O}_{3}$ and non- $\mathrm{O}_{3}$ seasons. Observation from AIRNow is shown as filled circles in the overlay plots of concentrations.

fugitive dust, the spatial distribution of large PMC emission is associated with the regions which have the significant overprediction in cooler months. In reality, the meteorological conditions could greatly impact the amount and characteristics of anthropogenic fugitive dust. For example, the snow cover and the soil moisture are important factors in calculating the dust emissions in SMOKE. However, the anthropogenic fugitive dust implemented in this GFSv15CMAQv5.0.2 system was not adjusted by the precipitation and snow cover. It will lead to a significant overestimation in the anthropogenic dust emission. The impact of the meteorological factor on anthropogenic fugitive dust emission and the $\mathrm{PM}_{2.5}$ prediction will be further discussed in Sect. 4 .
Murphy et al. (2017) found that secondary organic aerosols (SOAs) generated from anthropogenic combustion emissions were important missing PM sources in California prior to CMAQv5.2. The largest underpredictions of $\mathrm{PM}_{2.5}$ occur in the southeast in summer. Biogenic volatile organic compounds (BVOCs) and biogenic SOA (BSOA) are most active in the southeast region in summer. Many missing sources and mechanisms for SOA formation from BVOCs have been identified in recent years (Pye et al., 2013, 2015, 2017; Xu et al., 2018) and have resulted in significant improvements in predicting SOA in the southeast using CMAQv5.1 through v5.3. Anthropogenic emissions and aerosol inorganic compounds were found to have impacts on 

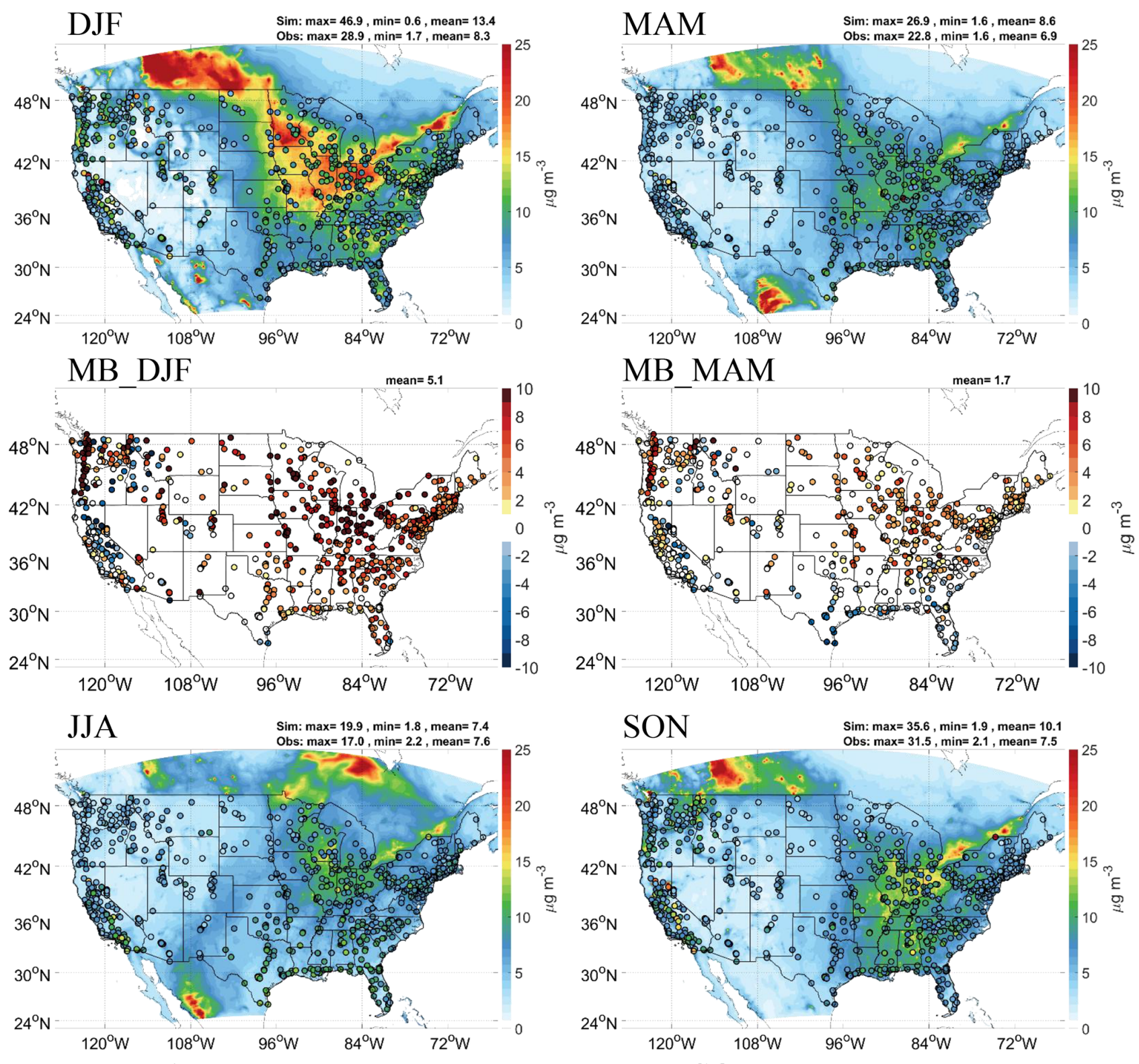

MB_JJA
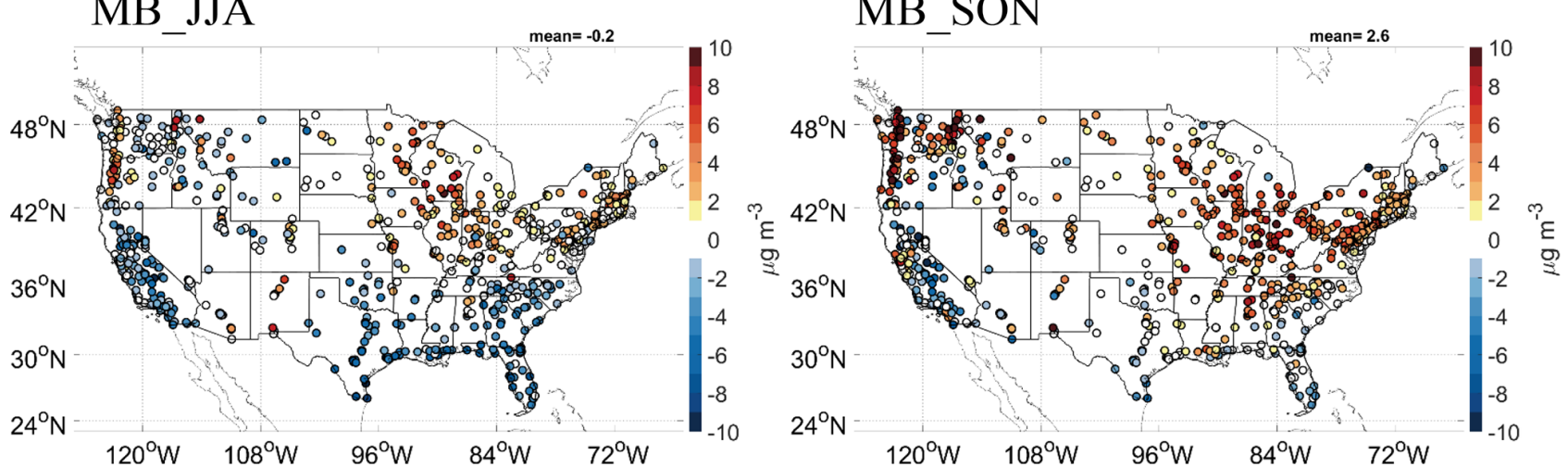

Figure 3. Forecasted seasonal daily $\mathrm{PM}_{2.5}$ by GFSv15-CMAQv5.0.2 overlaid observations from AIRNow and MB compared to observations from AIRNow. 


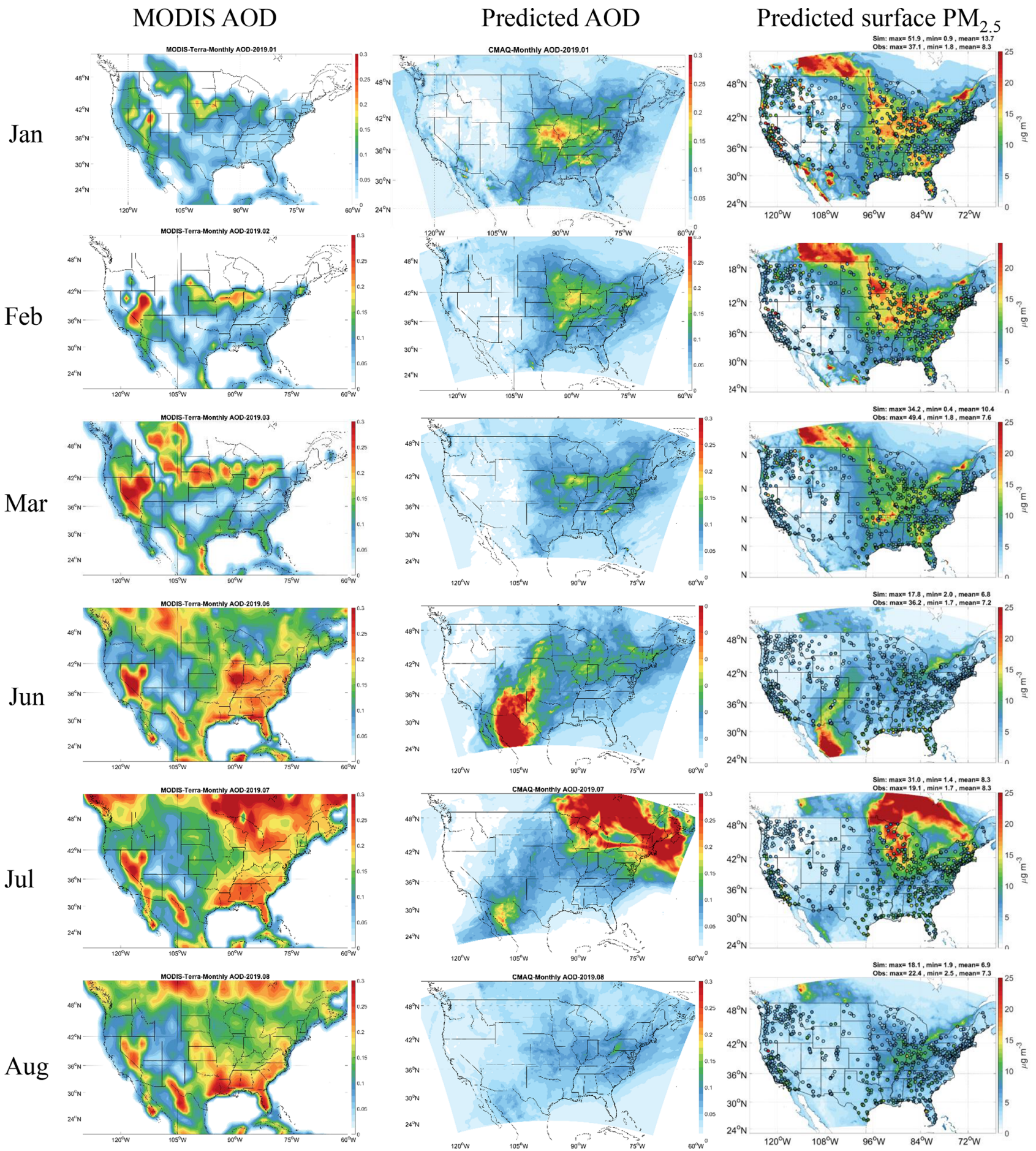

Figure 4. Monthly AOD from MODIS (left), predicted AOD from GFSv15-CMAQv5.0.2 (middle), and predicted surface 24h average $\mathrm{PM}_{2.5}$ (right).

BSOA (Carlton et al., 2018; Pye et al., 2018, 2019). Such interactions and mechanisms are not represented sufficiently in CMAQv5.0.2, further enhancing the biases in predicted $\mathrm{PM}_{2.5}$ in the southeast. The evaluation of predicted AOD compared to observations from MODIS is shown in Fig. 4.
High predicted AOD in the Midwest during cooler months shows consistency with MODIS and corresponds to high surface $\mathrm{PM}_{2.5}$ predictions. High predicted AOD is missing in California, corresponding to the underprediction of surface $\mathrm{PM}_{2.5}$ in California. In summer months, AOD is greatly un- 
derpredicted in California and the southeast, which may be caused by the previously mentioned missing sources of SOA.

\subsection{Categorical evaluation}

A categorical evaluation is conducted to quantify the accuracy of the GFSv15-CMAQv5.0.2 system in predicting events in which the air pollutants exceed moderate or unhealthy categories for the US AQI (http://www.airnow.gov, last access: 10 August 2020). The scatterplots for predicted and observed MDA8 $\mathrm{O}_{3}$ and $24 \mathrm{~h}$ average $\mathrm{PM}_{2.5}$ are shown in Fig. 5a and b, respectively. Numbers of the scatters in the four areas (a) to (d) are indicated in the Eqs. (1) and (2) in Sect. 2.2. The higher the FAR is, the more GFSv15CMAQv5.0.2 overpredicts the AQI leading to false air quality warnings. The higher the $H$ is, the more successfully the exceedances are captured by the GFSv15-CMAQv5.0.2 system. In this study, the thresholds for the two categories of "Moderate" and "Unhealthy for sensitive groups" are considered. Since 2018, they are defined as 55 and $70 \mathrm{ppb}$ for MDA8 $\mathrm{O}_{3}$ and 12 and $35.5 \mu \mathrm{g} \mathrm{m}^{-3}$ for $24 \mathrm{~h}$ average $\mathrm{PM}_{2.5}$. For comparison with previous studies, the historical thresholds are also included in the evaluation: 60 and $75 \mathrm{ppb}$ for MDA8 $\mathrm{O}_{3}$ and 15 and $35 \mu \mathrm{g} \mathrm{m}^{-3}$ for $24 \mathrm{~h}$ average $\mathrm{PM}_{2.5}$. The metrics in four categories, corresponding to four thresholds, are shown in Fig. 5c. Categorical performance under stricter AQI standards is better than under historical standards. For example, the FAR decreases from $48.4 \%$ to $41.4 \%$, and the $H$ increases from $42.7 \%$ to $45.8 \%$ with the Moderate threshold change from 60 to $55 \mathrm{ppb}$. This could be due to the better performance of the forecast system for values closer to the annual average level $(\sim 40 \mathrm{ppb})$. The scatters are more discrete for extreme values. When the thresholds of MDA8 $\mathrm{O}_{3}$ are closer to the average level, the categorical performance increases. A similar improvement in the FAR and $H$ for predicting categorical $24 \mathrm{~h}$ average $\mathrm{PM}_{2.5}$ can be found when the threshold changes from 15 to $12 \mu \mathrm{g} \mathrm{m}^{-3}$ : the FAR decreases from $80.1 \%$ to $70.3 \%$, and the $H$ increases from $52.8 \%$ to $57.6 \%$. However, the FAR is high (over $90 \%$ ) and the $H$ is much lower under the threshold of $35.5 \mu \mathrm{g} \mathrm{m}^{-3}$. It is because most of the false alarms occur when observed $24 \mathrm{~h}$ average $\mathrm{PM}_{2.5}$ is lower than $20 \mu \mathrm{g} \mathrm{m}^{-3}$ and the predicted values are higher than $20 \mu \mathrm{g} \mathrm{m}^{-3}$. It shows the poorer performance in correctly capturing the category of Unhealthy for sensitive groups due to the significant overprediction of $\mathrm{PM}_{2.5}$ in cooler months.

Major RT-AQF systems over the world were comprehensively reviewed in Zhang et al. (2012a, b). Here we include a comparison with more recent air quality forecasting studies. Table S3 summarizes air quality forecasting skills reported in the literature from assessments of other air quality forecasting studies from Canada (Moran et al., 2018; Russell et al., 2019), Europe (Struzewska et al., 2016; D'Allura et al., 2018; Podrascanin, 2019; Spiridonov et al., 2019; Stortini et al., 2020), East Asia (Lyu et al., 2017; Zhou et al., 2017;
Peng et al., 2018; Ha et al., 2020), and CONUS (Kang et al., 2010; Zhang et al., 2016; Lee et al., 2017), along with that from this work. For those studies with data assimilation in air quality forecasting, the performance from the raw results without data assimilation is presented. The performance in predicting $\mathrm{O}_{3}$ and $\mathrm{PM}$ vary greatly between model systems. The discrete and categorical performance in $\mathrm{O}_{3}$ prediction is not significantly better than that in PM prediction. $\mathrm{O}_{3}$ tends to be slightly overpredicted on an annual basis or for the warmer months. The annual NMB and Corr for $\mathrm{O}_{3}$ over the North America are $1.4 \%$ and 0.76 for 2010 in Moran et al. (2018), while they are $1.0 \%$ and 0.73 in this study. However, the performance in $\mathrm{PM}_{2.5}$ prediction varies greatly from our study. The $\mathrm{PM}_{2.5}$ for warmer months was moderately overpredicted in Russel et al. (2019), with the MBs ranging from 3.2 to $5.5 \mu \mathrm{g} \mathrm{m}^{-3}$. The categorical performance of GFSv15-CMAQv5.0.2 in predicting MDA8 $\mathrm{O}_{3}$ is similar to that of the previous NAQFC (Kang et al., 2010), in which the FAR and $H$ are $\sim 68 \%$ and $\sim 31 \%$ for the Unhealthy for sensitive groups category, and the $H$ is $\sim 47 \%$ for the Moderate category. The $H$ for $\mathrm{PM}_{2.5}$ also decreased greatly from $\sim 46 \%$ for the Moderate category to $\sim 21 \%$ for the Unhealthy for sensitive groups category, and the FAR was over $90 \%$ for the Unhealthy for sensitive groups category in Kang et al. (2010). The overpredicted $\mathrm{PM}_{2.5}$ was also found when using the historical 2005 NEI in a forecast for January 2015 (Lee et al., 2017). The performance was improved by updates of $2011 \mathrm{NEI}$ and real-time dust and wild fire emissions. It indicates the need to improve our emission inventory. As for the categorical performance in regions other than CONUS, the air quality standards vary (Oliveri Conti et al., 2017). For example, the National Ambient Air Quality Standards (NAAQSs), the Ambient Air Quality and Cleaner Air for Europe (CAFE) Directive (2008/50/EC), and the national ambient air quality standard (GB 3095-2012) are set up by the US, Europe, and China, respectively. Metrics also vary between studies. The primary forecasting products are $\mathrm{O}_{3}$ and $\mathrm{PM}_{10}$ from some forecasting systems instead of $\mathrm{O}_{3}$ and $\mathrm{PM}_{2.5}$ in this study. The threshold for a categorical evaluation of $\mathrm{O}_{3}$ used in D'Allura et al. (2018) was $83.0 \mu \mathrm{g} \mathrm{m}^{-3}$. The applied metrics of the false alarm ratio and probability of detection (POD) were defined the same as the FAR and $H$ used in our study. The FAR and POD were $36.14 \%$ and $71.16 \%$, respectively. The categorical evaluation of $\mathrm{PM}_{2.5}$ in $\mathrm{Ha}$ et al. (2020) was applied for four categories: (1) $0-15 \mu \mathrm{g} \mathrm{m}^{-3}$, (2) 16 $50 \mu \mathrm{g} \mathrm{m}^{-3}$, (3) $51-100 \mathrm{\mu g} \mathrm{m}^{-3}$, and (4) $>100 \mathrm{\mu g} \mathrm{m}^{-3}$. The overall FAR and detection rate for the four categories are $59.0 \%$ and $36.1 \%$, respectively. Although the metrics of the FAR and detection rate were defined for the four categories, rather than for every single category as in this study, the categorical performance is comparable with our results. In general, the discrete and categorical performance of $\mathrm{O}_{3}$ forecast in this study is comparable to that of the air quality forecasting systems in many regions of the world. However, the PM forecasts vary greatly between studies. While our GFSv15- 

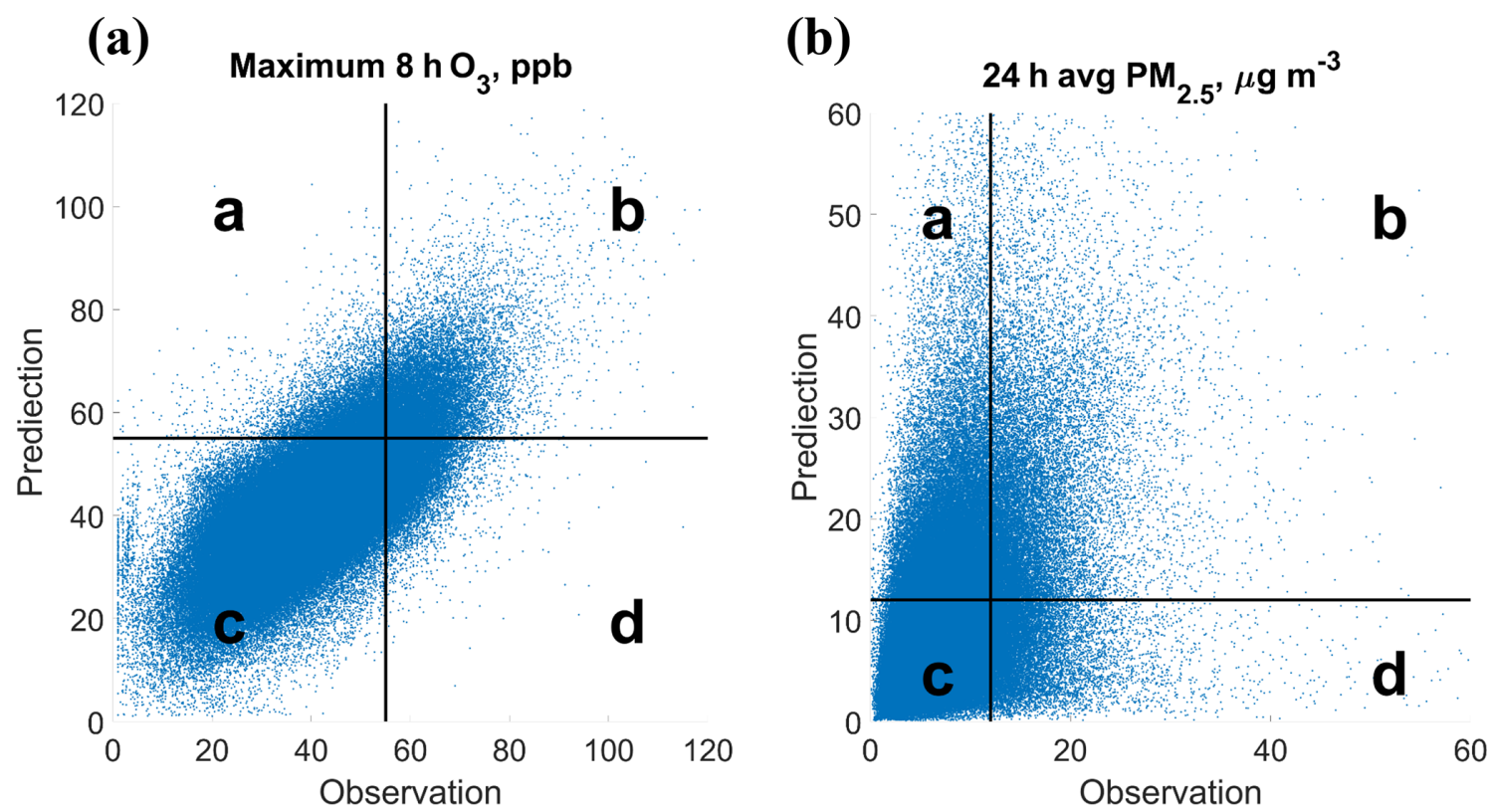

(c)

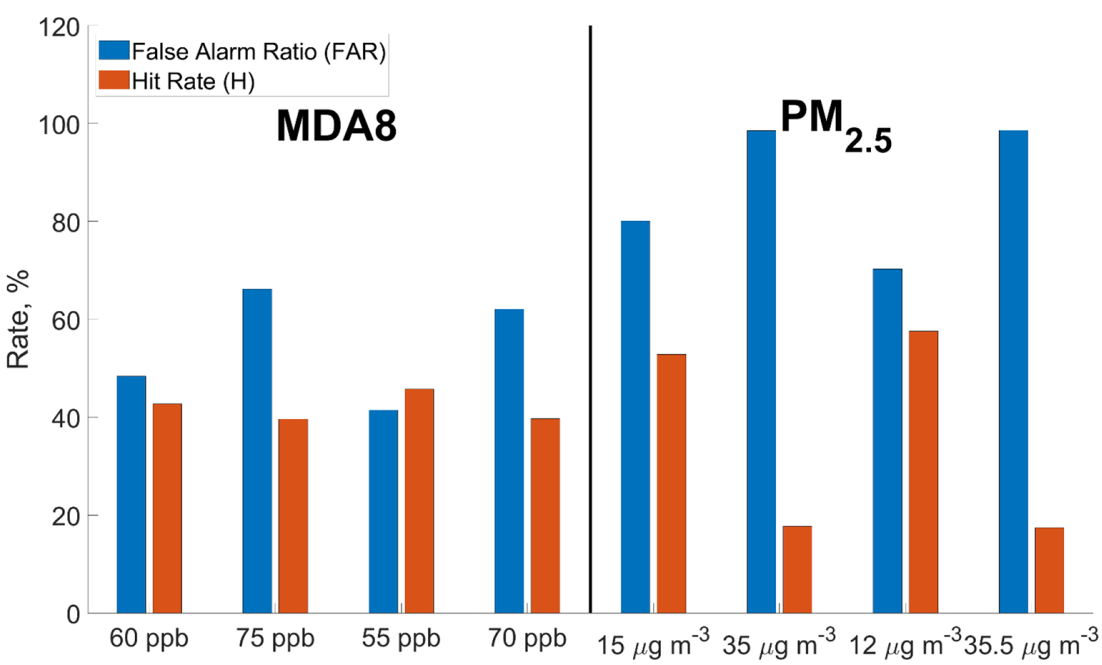

Figure 5. Categorical evaluation of MDA 8 and $24 \mathrm{~h}$ average $\mathrm{PM}_{2.5}$ : (a) scatterplot of predicted and observed MDA8; the scatters are divided into four areas using the threshold of $55 \mathrm{ppb}$ for both observation and prediction. (b) Scatterplot of predicted and observed $24 \mathrm{~h}$ average $\mathrm{PM}_{2.5}$; the scatters are divided into four areas using the threshold of $12 \mu \mathrm{g} \mathrm{m}^{-3}$ for both observation and prediction. (c) False alarm ratio (FAR) and hit rate $(H)$ in four categories for forecasts of MDA8 and $24 \mathrm{~h}$ average $\mathrm{PM}_{2.5}$.

CMAQv5.0.2 system shows consistent performance with the systems covering CONUS, the high FAR and low $H$ for the Unhealthy for sensitive groups category with higher thresholds indicate that the categorical performance could be further improved by addressing the significant overprediction during cooler months in this study.

\subsection{Region-specific evaluation}

As discussed in Sect. 3.2, biases in predicted $\mathrm{O}_{3}$ and $\mathrm{PM}_{2.5}$ vary from region to region. To further analyze the regionspecific performance of the GFSv15-CMAQv5.0.2 system, an evaluation for 10 regions within CONUS is conducted. By identifying the detailed characteristics of region-specific biases and indicating the underlying causes for such biases, this section aims to help the NAQFC to improve its forecast ability for specific regions.

Figure 6 shows the annual model performance for MDA8 $\mathrm{O}_{3}$ and $24 \mathrm{~h}$ average $\mathrm{PM}_{2.5}$ in the 10 CONUS regions. In Sect. 3.2, a slight underprediction of MDA8 $\mathrm{O}_{3}$ on an annual basis was found over the CONUS. MDA8 $\mathrm{O}_{3}$ is underpredicted in most of the regions except regions 2 , 4, and 6 (Fig. 6a). The overpredictions in regions 4 and 6 are mostly from the large biases near the coast area during the $\mathrm{O}_{3}$ sea- 
(a)
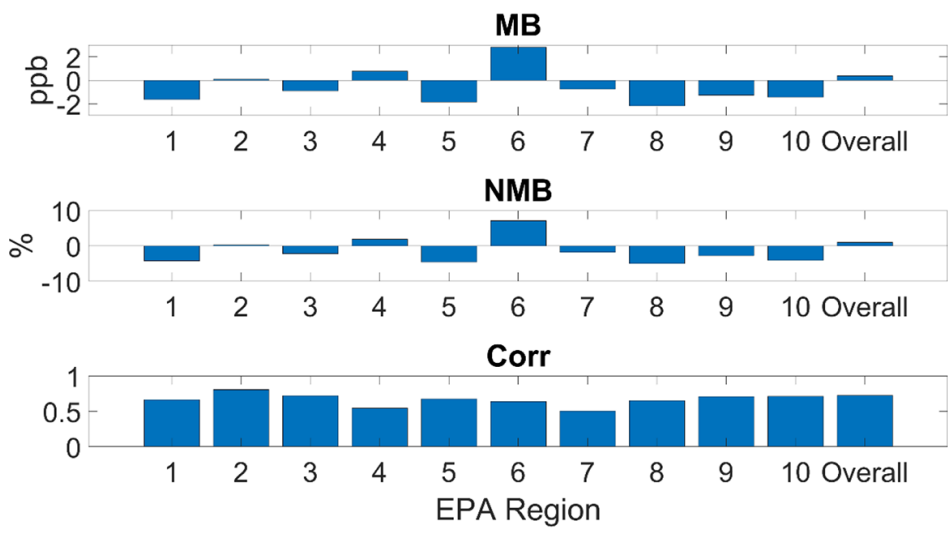

(c)
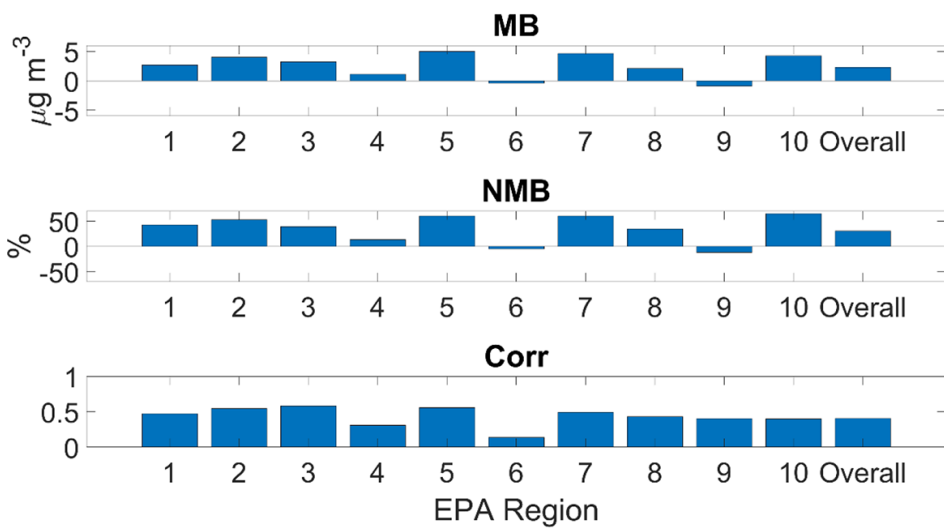

(b)

Annual Performance of MDA8 from FV3-CMAQv502

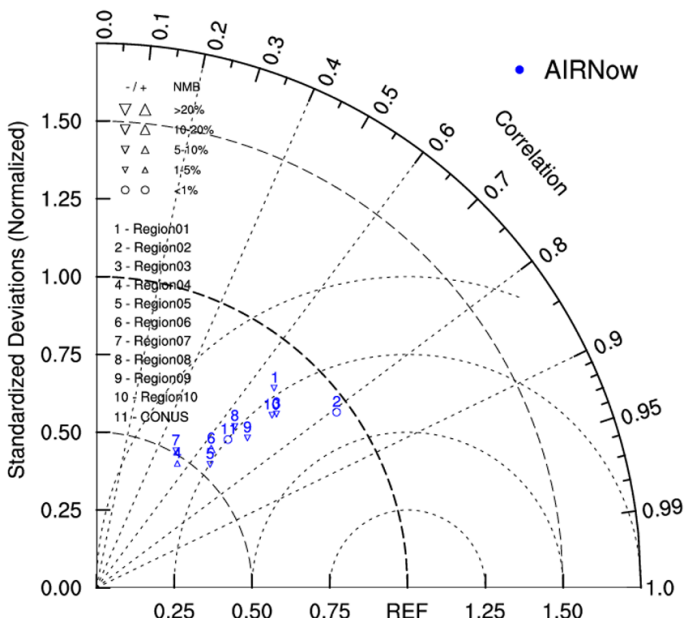

(d)

Annual Performance of $24 \mathrm{~h}$ avg PM2.5 from FV3-CMAQv502

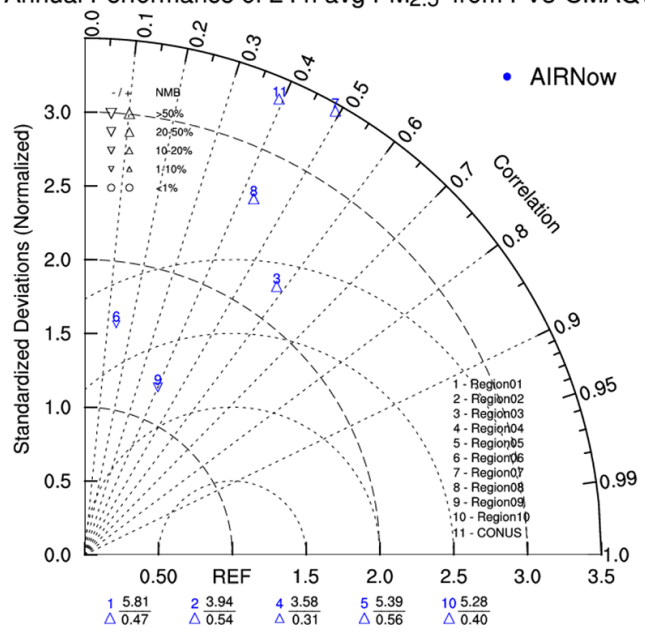

Figure 6. Annual performance of MDA8 in 10 CONUS regions (a); Taylor diagram for annual performance of MDA8 (b); annual performance of $24 \mathrm{~h}$ average $\mathrm{PM}_{2.5}$ in 10 CONUS regions (c); Taylor diagram for annual performance of $24 \mathrm{~h}$ average $\mathrm{PM}_{2.5}$. Outliers represent regions with NSDs $>3.5(\mathbf{d})$.

son. Correlations between predictions and observations in most of the regions are higher than 0.6, except for 0.55 in region 4 and 0.50 in region 7 . Poor performance in regions 4 and 7 is illustrated by the Taylor diagram (Fig. 6b). Small Corr and NSD result in the markers of regions 4 and 7 lying farthest from the reference point. The amplitude of variability of the predicted MDA8 $\mathrm{O}_{3}$ is smaller than the observed values in all the regions, especially in regions 4 and 7 . The performance in region 2 is the best, with the smallest MB or $\mathrm{NMB}$, the highest Corr, and similar variability in predictions and observations. The time series of the MDA8 $\mathrm{O}_{3}$ for the 10 regions during 2019 is shown in Fig. S6 in the Supplement. Regions 1, 2, 4, and 6 show different results for the $\mathrm{O}_{3}$ season and the non- $\mathrm{O}_{3}$ season: GFSv15-CMAQv5.0.2 tends to overpredict MDA8 $\mathrm{O}_{3}$ during the $\mathrm{O}_{3}$ season and underpredicts it during the non- $\mathrm{O}_{3}$ season. The underprediction during spring months, which is indicated in Sect. 3.2, can be also found in most of the regions with obvious gaps between observed and predicted curves in March and April. The lowest $\mathrm{O}_{3}$ predictions occur at 05:00 local standard time (LST) in most of the regions (Fig. S7 in the Supplement). For regions 4 and 6, significant overprediction occurs not only during the $\mathrm{O}_{3}$ season for MDA8 $\mathrm{O}_{3}$ (which mainly occurs during the daytime) but also during the nighttime. During the non- $\mathrm{O}_{3}$ season, the biases in predicting MDA8 $\mathrm{O}_{3}$ for regions 4 and 6 are small and consistent with good daytime predictions. However, $\mathrm{O}_{3}$ is still overpredicted during the nighttime in these regions, associated with the collapse of the boundary layer and difficulty in simulating its time and magnitude (Hu et al., 2013; Cuchiara et al., 2014; Pleim et al., 2016). 
Consistent with the analysis in Sect. 3.2, $\mathrm{PM}_{2.5}$ is significantly overpredicted in most of the regions except in regions 4, 6, and 9 (Fig. 6c). The underprediction during warmer months, likely due to missing sources and mechanisms for BSOA, compensates for the annual biases in regions 4 and 6 , leading to smaller MBs or NMBs but low correlations in these regions. The variability in predictions is much larger than in observations, with the NSDs $>1$ for all regions (Fig. 6d). The forecast system has the best performance in region 9 with an NSD of 1.2, an NMB of $-12.0 \%$, and a Corr of 0.40. Figure S8 in the Supplement shows the time series of $24 \mathrm{~h}$ average $\mathrm{PM}_{2.5}$ in the 10 CONUS regions. The gaps between observed and predicted curves are large in cooler months, but the GFSv15-CMAQv5.0.2 system has relatively good performance in warmer months for most of the regions. Less overprediction is found in regions 6 and 9 during cooler months, and those regions generally show the best performance (see Taylor diagram). The different biases across the regions further indicate that multiple factors likely contribute to them.

\section{Discussion}

\subsection{Meteorology-chemistry relationships}

We further quantify the meteorology-chemistry relationships by conducting the region-specific evaluation of the meteorological variables. The regional performance for the major variables is shown in Fig. S9 in the Supplement. The regional biases in $T 2$ predictions show high correlation with the regional biases in MDA8 $\mathrm{O}_{3}$. It indicates that the cold biases in the Midwest (including region 5) and the warm biases near the Gulf coast (including regions of 4 and 6) are important factors for the $\mathrm{O}_{3}$ underprediction and overprediction in those regions, respectively. The $\mathrm{O}_{3}$-temperature relationship was found (Sillman and Samson, 1995; Sillman, 1999). $\mathrm{O}_{3}$ is expected to increase with increasing temperature within a specific range of temperature (Bloomer et al., 2009; Shen et al., 2016). The surface $\mathrm{MDA}_{8} \mathrm{O}_{3}$-temperature relationship was found at approximately $3-6 \mathrm{ppb} \mathrm{K}^{-1}$ in the eastern US (Rasmussen et al., 2012). According to such relationships, the biases in $T 2$ predictions could explain a large portion of the $\mathrm{O}_{3}$ biases. Heavy convective precipitation and tropical cyclones have a large impact in the southeastern US, which covers mainly regions 4 and 6 . Therefore, the performance in precipitation predictions is lower in those two regions compared to other regions as we discussed regarding the model performance in capturing short-term heavy rains during summer seasons in Sect. 3.1. Meanwhile, the performance in wind predictions in regions 4 and 6 is relatively poor. Such performance in the meteorological predictions is consistent with the mixed performance in $\mathrm{PM}_{2.5}$ prediction in regions 4 and 6 . The low temporal agreement shown as correlations of predicted $\mathrm{PM}_{2.5}$ in those two regions can be attributed to the discrepancy in meteorological inputs, mainly in precipitation and wind.

\subsection{Major biases in $\mathrm{O}_{3}$ predictions}

Prediction and simulation of $\mathrm{O}_{3}$ in coastal or marine areas are impacted by halogens chemistry and emissions (Adams and Cox, 2002; Sarwar et al., 2012; Liu et al., 2018), including bromine and iodine chemistry (Foster et al., 2001; Sarwar et al., 2015; Yang et al., 2020) and oceanic halogen emissions (Watanabe, 2005; Tegtmeier et al., 2015; He et al., 2016). CMAQv5.0.2 only has simple chlorine chemistry for CB05 mechanisms, and the reduction of $\mathrm{O}_{3}$ by reaction with bromine and iodine is not included in CMAQv5.0.2. Iodidemediated $\mathrm{O}_{3}$ deposition over seawater and detailed marine halogen chemistry has been found to reduce $\mathrm{O}_{3}$ by $1-4 \mathrm{ppb}$ near the coast (Gantt et al., 2017), suggesting that the missing halogen chemistry and $\mathrm{O}_{3}$ deposition processes contribute to overpredicted $\mathrm{O}_{3}$ in coastal and marine areas seen here. Coastal and marine areas are also impacted by air-sea interaction processes, which are simply represented in the current meteorological models without coupling oceanic models ( $\mathrm{He}$ et al., 2018; Y. Zhang et al., 2019a, b). For example, coastal $\mathrm{O}_{3}$ mixing ratios are impacted by predicted sea surface temperatures and land-sea breezes through their influence on chemical reaction conditions and diffusion processes. As discussed in Sects. 3.1 and 4.1, the GFSv15-CMAQv5.0.2 system has poorer performance in predicting the meteorological variables in regions of 4 and 6 , which could contribute to biases in $\mathrm{O}_{3}$ predictions directly or indicate missing land-sea breezes and thus missing transport effects in the GFSv15CMAQv5.0.2 air quality forecasting system.

In addition to the impact of meteorological biases and missing halogen chemistry on the $\mathrm{O}_{3}$ overprediction near the Gulf coast, the overestimated volatile organic compound (VOC) emission could enhance the $\mathrm{O}_{3}$ biases. The anthropogenic VOC emissions continuously decrease from historical NEIs to the 2016 NEI (http://views.cira.colostate.edu/wiki/wiki/10202/ inventory-collaborative-2016v1-emissions-modeling-90platform, last access: 10 October 2020). We compare the VOC emissions between the $2016 \mathrm{NEI}$ and the emissions used in this study. The difference in the elevated source of pt_oilgas is shown in Fig. S10 in the Supplement. The Gulf coast is impacted by the oil and gas sector due to the oil and gas fields and the exploration activity near it. By comparing the newer NEI to the current NEI we used in the system, we found that the overestimation of the VOCs could be one aspect of the $\mathrm{O}_{3}$ overprediction near the Gulf Coast because we only project the $\mathrm{SO}_{2}$ and $\mathrm{NO}_{x}$ from the 2005 NEI to 2019 but we do not project the VOCs for the elevated sources. The monthly VOC emissions from the pt_oilgas sector for July in regions 4 and 6 are $2876.0 \mathrm{tmonth}^{-1}$, while they are $2497.0 \mathrm{tmonth}^{-1}$ in the $2016 \mathrm{NEI}$. The reduction is mainly located along the coastline, where the significant 
overprediction takes place. It indicates the complicated effect of meteorological biases, missing gas-phase chemistry, and the overestimation of emissions on the $\mathrm{O}_{3}$ prediction in these regions.

The $\mathrm{O}_{3}$ concentration is underpredicted for the northeast, mid-Atlantic, Midwest, mountainous states, and northwest (mainly corresponding to the regions 1, 3, 5, 8, and 9) during the non- $\mathrm{O}_{3}$ season. A large difference in dry-deposition algorithms between CMAQv5.0.2 and other common parameterizations was reported (Park et al., 2014; Wu et al., 2018). A large discrepancy between modeled dry-deposition velocity of $\mathrm{O}_{3}$ by CMAQv5.0.2 and the observation during winter was shown and attributed to the deposition to snow surface. An improvement was indicated in revising the treatment of deposition to snow, vegetation, and bare ground in CMAQv5.0.2. Lower deposition to snow was found to improve the consistency between the $\mathrm{O}_{3}$ deposition modeled by CMAQv5.0.2 and the observations. Therefore, the dry-deposition module in v5.0.2 needs to be updated and improved for more accurate representation of low-moderate $\mathrm{O}_{3}$ mixing ratios (Appel et al., 2021). For the cases in this study, the predicted snow cover for the months of January and April in winter and spring are shown in Fig. 7a and b. The underpredicted $\mathrm{O}_{3}$ during the non- $\mathrm{O}_{3}$ season may be caused by the overestimated $\mathrm{O}_{3}$ deposition to snow in the northern regions, corresponding to the previous regions $1,3,5,8$, and 9 . The mixed effects of the temperature- $\mathrm{O}_{3}$ relationship discussed above and the large deposition to snow contribute to the moderate $\mathrm{O}_{3}$ underpredictions.

\subsection{Major biases in $\mathbf{P M}_{2.5}$ predictions}

Major biases in $\mathrm{PM}_{2.5}$ prediction are distinguished for warmer and cooler months in Sect. 3. To further analyze the underlying causes for varied patterns and performance on a season- and region-specific basis, diurnal evaluations for $\mathrm{PM}_{2.5}$ and chemical components of $\mathrm{PM}_{2.5}$ during the $\mathrm{O}_{3}$ season and the non- $\mathrm{O}_{3}$ season are shown in Fig. 8. GFSv15CMAQv5.0.2 has a large seasonal variation in diurnal $\mathrm{PM}_{2.5}$, inconsistent with the observation. While $\mathrm{PM}_{2.5}$ is underpredicted during daytime in regions $4,6,8$, and 9 during the $\mathrm{O}_{3}$ season, $\mathrm{PM}_{2.5}$ is always overpredicted across the day during the non- $\mathrm{O}_{3}$ season except for region 9. Increased organic carbon (OC), particulate nitrates, soil and unspecified coarsemode components contribute to most of the increase in predicted total $\mathrm{PM}_{2.5}$. The general cold biases over CONUS, especially in region 5, could make the GFSv15-CMAQv5.0.2 system predict higher nitrate particulates, leading to a larger increase in $\mathrm{PM}_{2.5}$ from the $\mathrm{O}_{3}$ season to the non- $\mathrm{O}_{3}$ season. Emissions vary from month to month in the year (Fig. S11a in the Supplement). There are larger emissions for $\mathrm{NH}_{3}$, $\mathrm{NO}_{x}$, VOC, primary coarse $\mathrm{PM}$, and primary $\mathrm{PM}_{2.5}$ in the $\mathrm{O}_{3}$ season compared to the non- $\mathrm{O}_{3}$ season. Primary organic carbon (POC) emissions are higher in the $\mathrm{O}_{3}$ season. Changes in emissions are not fully consistent with the changes in $\mathrm{PM}_{2.5}$ components, indicating that other biases or uncertainty could also contribute to the significant overprediction during the non- $\mathrm{O}_{3}$ season. For example, the implementation of a bidirectional flux of $\mathrm{NH}_{3}$ and the boundary layer mixing processes under more stable conditions (during the non- $\mathrm{O}_{3}$ season) in the GFSv15-CMAQv5.0.2 system need to be further studied. Pleim et al., $(2013,2019)$ found that the $\mathrm{NH}_{3}$ fluxes and concentrations could be better simulated and the monthly variations in $\mathrm{NH}_{3}$ concentrations were larger compared to the raw model by implementing the bidirectional flux of $\mathrm{NH}_{3}$. The absolute biases for diurnal $\mathrm{PM}_{2.5}$ are generally larger during nighttime in most of the regions, except for region 9. This is consistent with the analysis by Appel et al. (2013), which suggested that the efforts of improving nighttime mixing in CMAQv5.0 are further needed, further indicating the need for improvements of CMAQ in predicting dispersion and mixing of air pollutants under stable boundary layer conditions. The forecast system gives the highest PM predictions at two peaks during the day: 06:00 and 19:00 in the $\mathrm{O}_{3}$ season and 07:00 and 20:00 in the non- $\mathrm{O}_{3}$ season at LST, respectively, corresponding to the shifting between daylight saving time and LST. The two diurnal peaks are caused by the diurnal pattern of emissions (Fig. S11b). PM is mostly emitted during the daytime from 06:00 to 18:00. With the development of the boundary layer during the daytime, surface $\mathrm{PM}_{2.5}$ concentrations will be reduced by the diffusion. During dawn and dusk, the boundary layer transits between stable and well-mixed conditions. The increased emission and secondary production of $\mathrm{PM}_{2.5}$ will be accumulated within the boundary layer, causing the high peaks during dawn and dusk.

The variation in predicted $\mathrm{PM}_{2.5}$ composition between cooler and warmer months indicates that major seasonal biases are caused by multiple factors. We introduce the Air Quality System (AQS) dataset for the evaluation of daily $\mathrm{PM}_{2.5}$ composition to provide additional insight into the specific reasons. Figure 9 shows the biases of the key $\mathrm{PM}_{2.5}$ composition for the cooler month of January and warmer month of July. While the overall mean biases of $\mathrm{PM}_{2.5}$ composition, including elemental carbon (EC), ammonium $\left(\mathrm{NH}_{4}^{+}\right)$, and nitrate $\left(\mathrm{NO}_{3}^{-}\right)$, are within $\pm 0.5 \mu \mathrm{g} \mathrm{m}{ }^{-3}$ for all months of the year, the major biases in $\mathrm{PM}_{2.5}$ predictions are mostly contributed by OC, soil components (SOIL), and sulfate $\left(\mathrm{SO}_{4}^{2-}\right)$. The soil components are estimated using the Interagency Monitoring of Protected Visual Environments (IMPROVE) equation and specific constituents (Appel et al., 2013). During a cooler month, the significant overprediction in $\mathrm{PM}_{2.5}$ is mainly attributed to the overprediction in OC and SOIL. During warmer months, the overprediction of SOIL and sulfate compensates for the overall underprediction in OC in v5.0.2, leading to the moderate $\mathrm{PM}_{2.5}$ underprediction in the southeast but slight overprediction in the Midwest, mid-Atlantic, and the northeast. These high $\mathrm{PM}_{2.5}$ SOIL concentrations are consistent in spatial characteristics with large emissions of anthropogenic primary $\mathrm{PM}_{2.5}$ and 
(a)

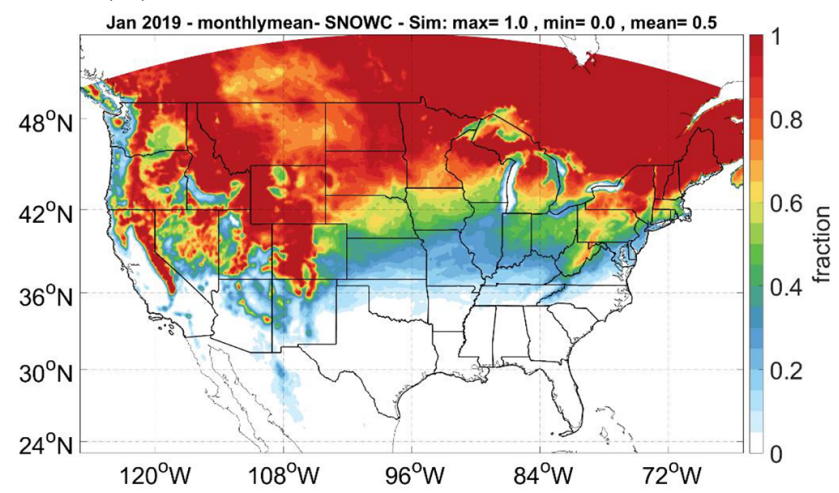

(c)

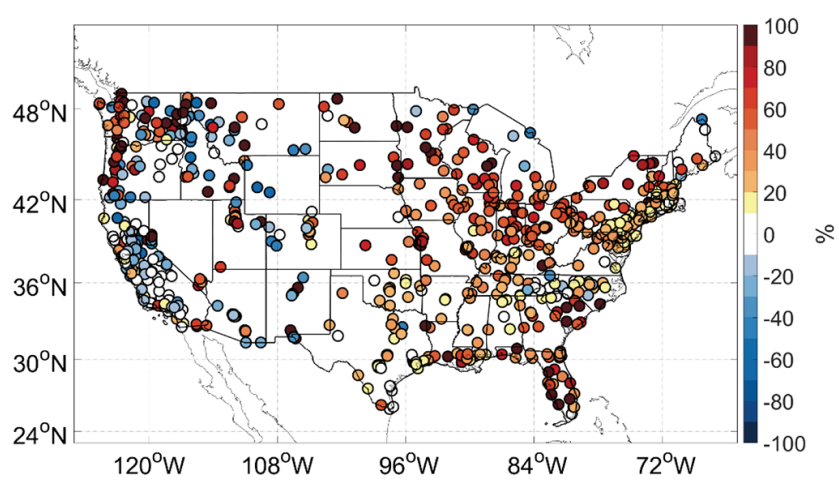

(b)

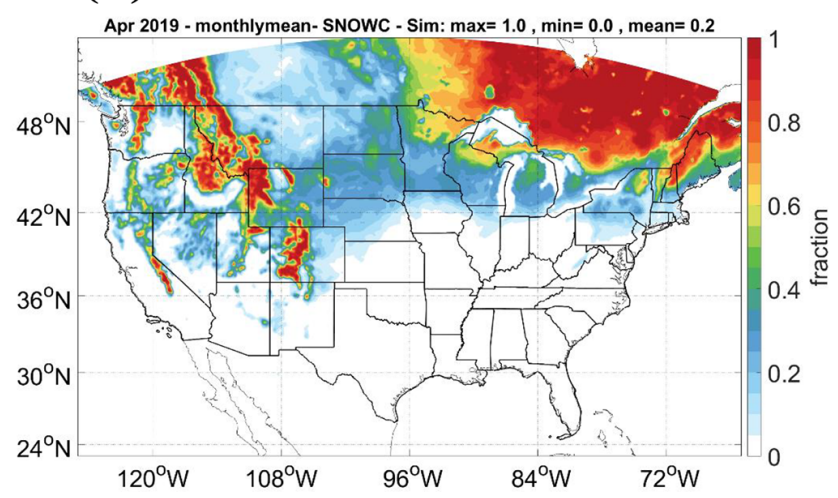

(d)

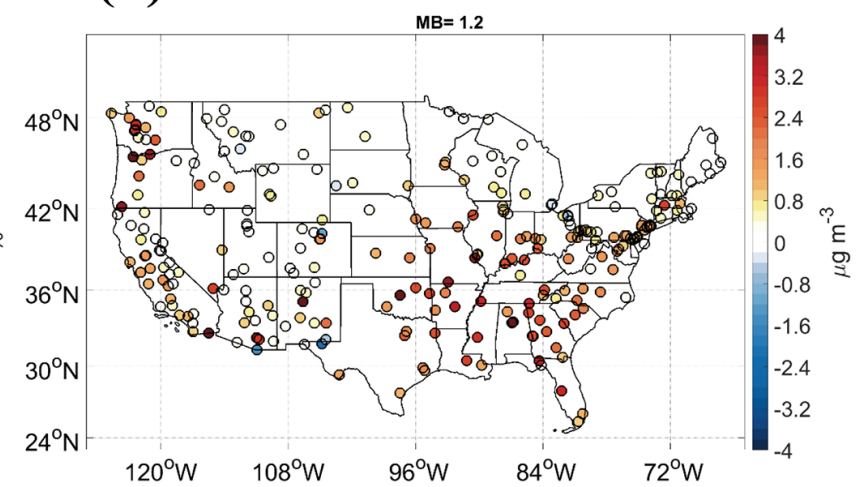

Figure 7. The predicted average snow cover for (a) January and (b) April. (c) The difference in NMBs of PM 2.5 by adjusting PM emission for January. Positive values stand for improvement in biases with NMBs closer to 0. (d) MBs in $\mathrm{PM}_{2.5}$ soil composition with adjustment of PM emission for January.

primary coarse PM in the Midwest, northeast, and northwest. The underprediction in $\mathrm{PM}_{2.5}$ OC during summer compensates for the overestimation in dust during cooler months, resulting in the overall biases with an annual NMB of $30.0 \%$.

The large emissions of anthropogenic primary coarse PM as well as the wind-blown dust are the major sources for predicted $\mathrm{PM}_{2.5}$ SOIL components. Appel et al. (2013) indicated CMAQ overpredicted soil components in the eastern United States partially due to the anthropogenic fugitive dust and wind-blown dust emissions. The overprediction in $\mathrm{PM}_{2.5}$ soil compositions by our forecast system could mainly be attributed to the overestimation of the anthropogenic fugitive dust emission because the meteorological conditions were not included in processing the anthropogenic fugitive dust sector. The dust-related components of aluminum, calcium, iron, titanium, silicon, and coarse-mode particles are overestimated in the regions with snow and precipitation, especially during winter, early spring, and late autumn with snow cover in the north, which contributes to the $\mathrm{PM}_{2.5}$ overprediction, with a more significant temporal-spatial pattern in the north US during cooler months.
An adjustment of precipitation and snow cover for fugitive dust was implemented in the operational NAQFC. The dust-related PM emissions will be cleaned up using a factor of 0.01 when the snow cover is higher than $25 \%$ or the hourly precipitation is higher than $0.1 \mathrm{mmh}^{-1}$ before they are used as input for CMAQv5.0.2 forecast. We conduct a sensitivity simulation for January 2019 using the GFSv15CMAQv5.0.2 system with the adjustment implemented in the operational NAQFC. Figure $7 \mathrm{c}$ shows that the $\mathrm{PM}_{2.5}$ overprediction in the northern regions $1,2,5$, and 10 during January is greatly improved corresponding to the spatialtemporal characteristics of snow cover. The monthly MB and NMB for January improves from $5.5 \mu \mathrm{g} \mathrm{m}^{-3}$ and $66.9 \%$ to $2.1 \mu \mathrm{g} \mathrm{m}^{-3}$ and $24.0 \%$, respectively. The improvement is mainly attributed to the decrease in overpredictions in $\mathrm{PM}_{2.5}$ soil components, with MBs decreased from 3.3 to $1.2 \mu \mathrm{g} \mathrm{m}^{-3}$ for January (Fig. 7d). The overprediction in the northeast and northwest during spring is expected to be improved by the suppression of the fugitive dust by the snow during early spring. This indicates the importance of including the meteorological forecast in processing the emission of anthro- 
(a)

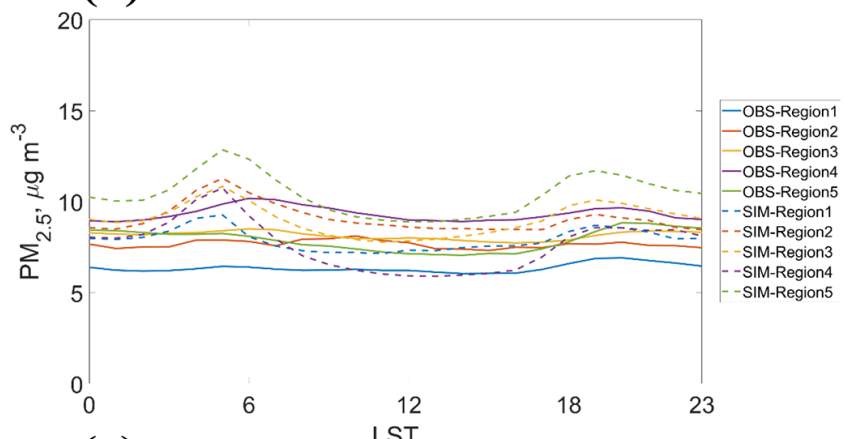

(c)

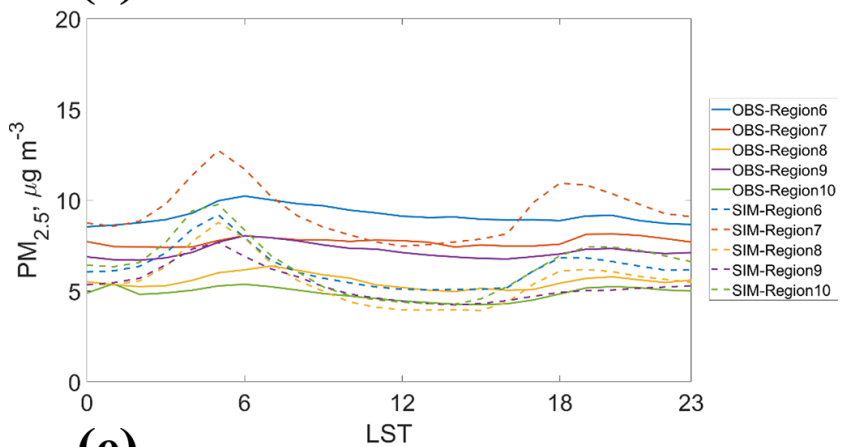

(e)

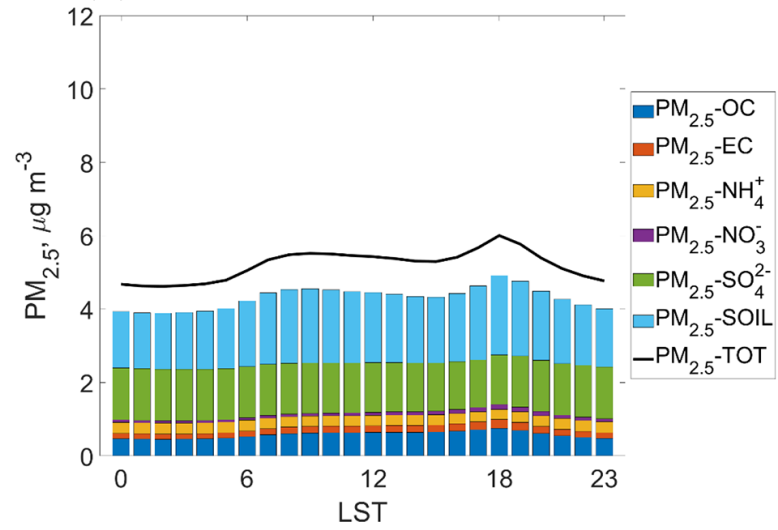

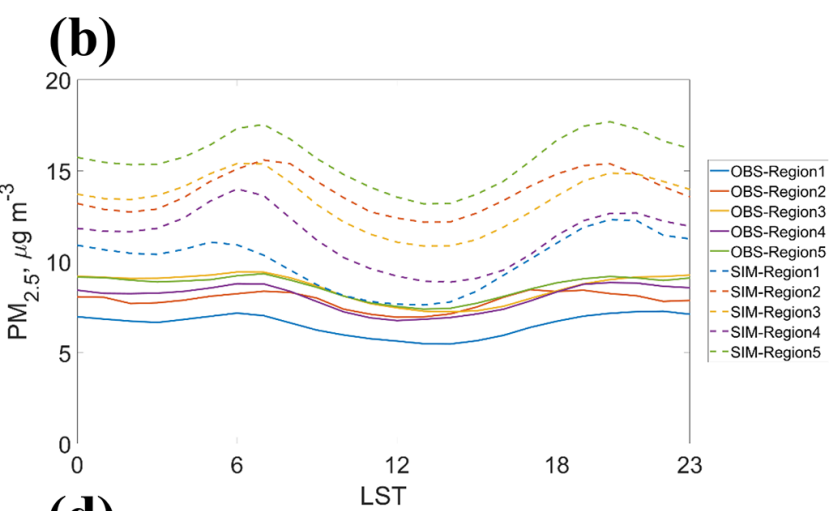

(d)

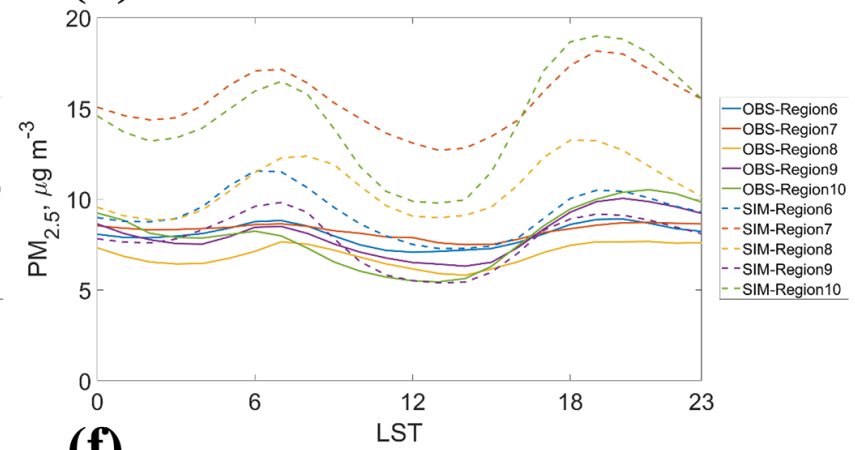

(f)

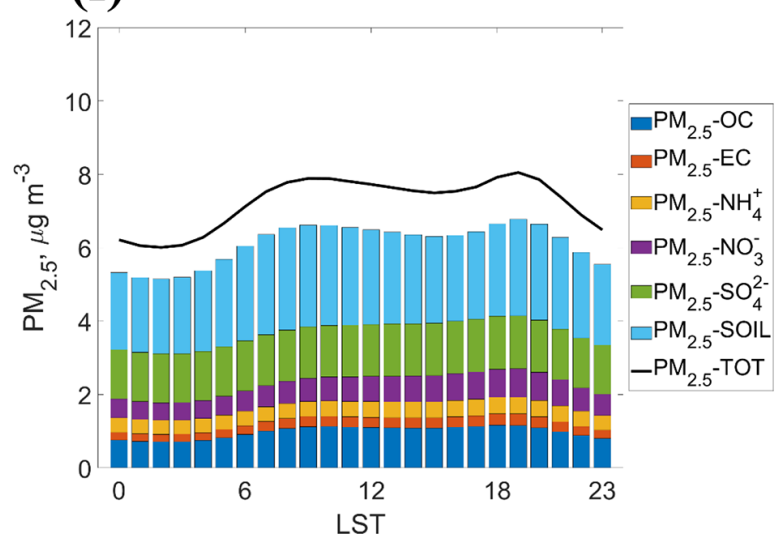

Figure 8. Diurnal $\mathrm{PM}_{2.5}$ in (a) the $\mathrm{O}_{3}$ season for regions 1 to 5; (b) the non- $\mathrm{O}_{3}$ season for regions 1 to 5 ; (c) the $\mathrm{O}_{3}$ season for regions 6 to 10 ; (d) the non- $\mathrm{O}_{3}$ season for regions 6 to 10. Solid curves are observed values and dashed curves are predicted values. Average of predicted $\mathrm{PM}_{2.5}$ and components of $\mathrm{PM}_{2.5}$ within CONUS in (e) the $\mathrm{O}_{3}$ season and (f) the non- $\mathrm{O}_{3}$ season.

pogenic fugitive dust. It should be calculated inline or be adjusted by the meteorological forecast.

In CMAQv5.0.2, the primary organic aerosol (POA) is processed as non-volatile. The emissions of semivolatile and intermediate-volatility organic compounds (S/IVOCs) and their contributions to the SOA are not accounted for in the aerosol module. In the recent versions of CMAQ, two approaches linked to POA sources have been implemented. One introduces semivolatile partitioning and gas-phase oxidation of POA emissions. The other one (called pcSOA) accounts for multiple missing sources of anthropogenic SOA formation, including potential missing oxidation pathways and emissions of IVOCs. These two improvements lead to increased organic carbon concentration in summer but a decreased level in winter. The changes vary by season as a result of differences in volatility (as dictated by temperature and boundary layer height) and reaction rate between winter and summer. Therefore, the missing S/IVOCs and related SOA chemistry in v5.0.2 are key reasons for the OC overprediction and underprediction during cooler and warmer months, respectively. 
(a)

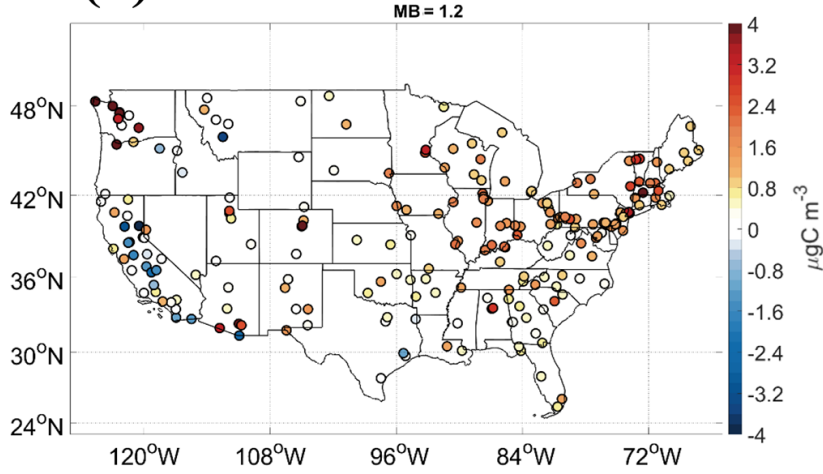

(c)

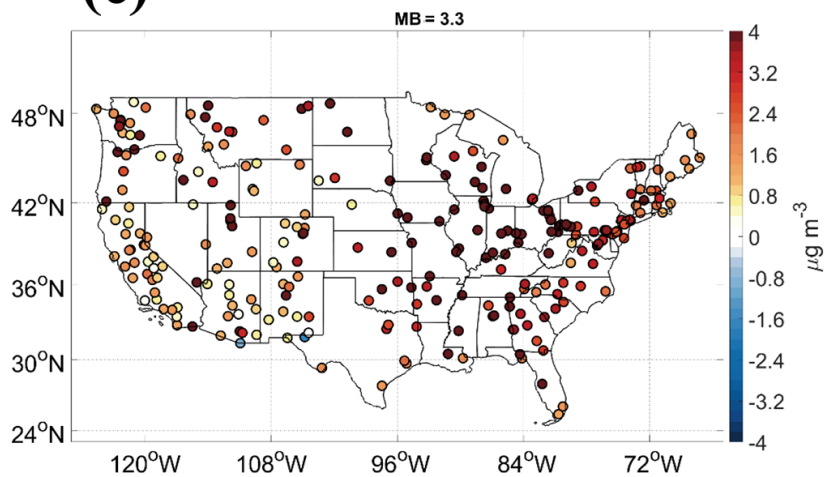

(e)

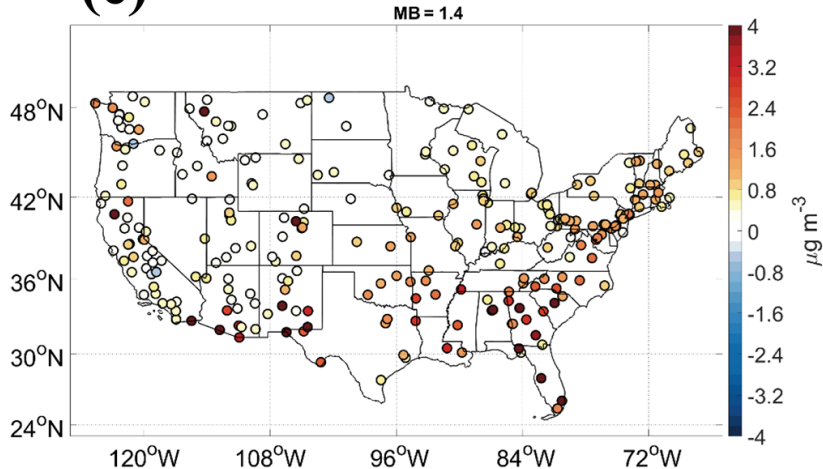

Figure 9. Mean biases in $\mathrm{PM}_{2.5}$ compositions: (a) OC for January, (b) January, and (f) sulfate for July.

\section{Conclusions}

In this work, the air quality forecast for the year 2019 predicted by the offline-coupled GFSv15-CMAQv5.0.2 system is comprehensively evaluated. The GFSv15-CMAQv5.0.2 system is found to perform well in predicting surface meteorological variables (temperature, relative humidity, and wind) and $\mathrm{O}_{3}$ but has mixed performance for $\mathrm{PM}_{2.5}$. Moderate cold biases and wet biases are found in the spring season, especially in March. While the GFSv15-CMAQv5.0.2 system can generally capture the monthly accumulated precipitation compared to remote-sensing and ensemble datasets, tempo-

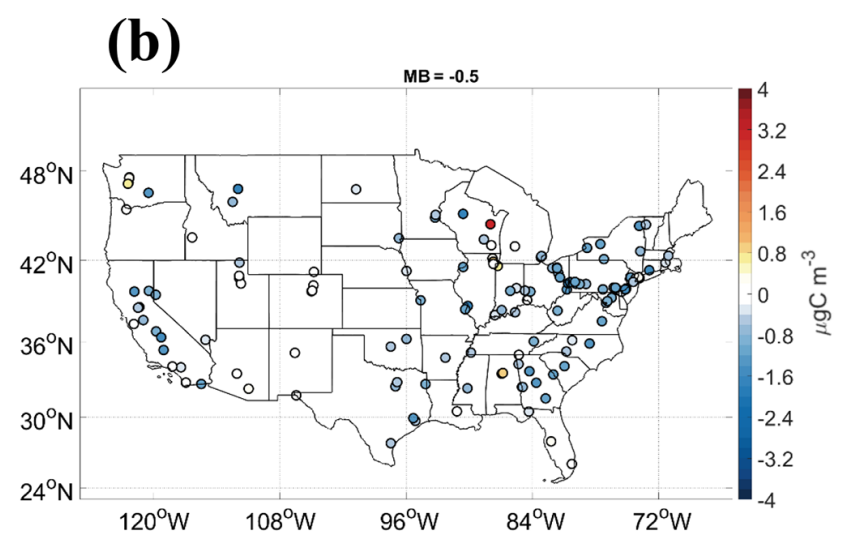

(d)

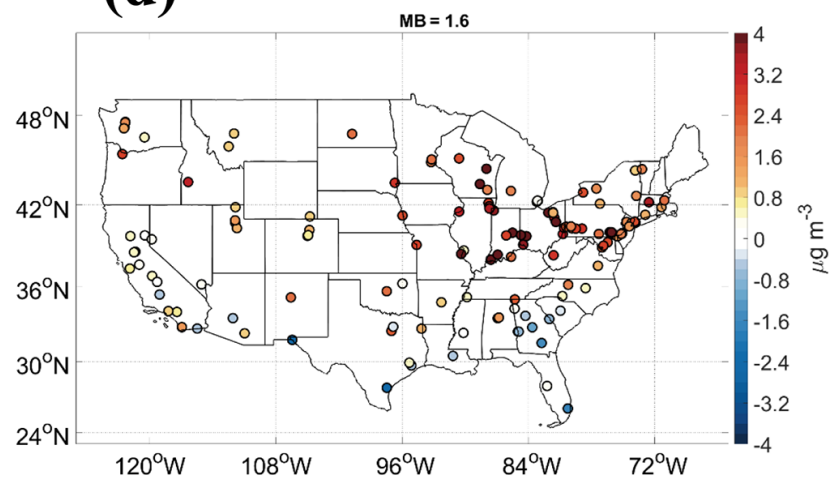

(f)

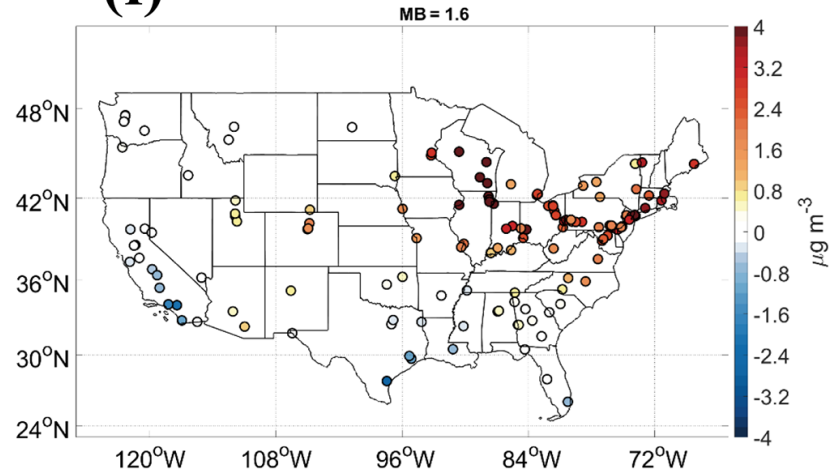

(b) OC for July, (c) SOIL for January, (d) SOIL for July, (e) sulfate for ral distributions of hourly precipitation show less consistency with in situ monitoring data.

MDA $8 \mathrm{O}_{3}$ is slightly overpredicted and underpredicted in ozone and the non- $\mathrm{O}_{3}$ seasons, respectively. The significant overprediction near the Gulf Coast is associated with the missing halogen chemistry, overestimated emission of precursors, and the poorer performance in meteorological performance, which could be attributed to the missing model representation of the air-sea interaction processes. It compensates for underprediction in the west and Midwest in the $\mathrm{O}_{3}$ season for nationwide metrics. A slight underprediction is found during the non- $\mathrm{O}_{3}$ season, indicating the impact of 
cold biases of $T 2$ and the overestimated dry deposition to the snow surface. GFSv15-CMAQv5.0.2 has poorer performance in predicting $\mathrm{PM}_{2.5}$, compared to the performance for $\mathrm{O}_{3}$. Significant overpredictions are found in cooler months, especially in winter. The largest overprediction is shown in the Midwest and the states of Washington and Oregon due mainly to high concentrations of predicted fine fugitive, coarse-mode, and OC compositions. The lacking suppression of snow cover on anthropogenic fugitive dust emission and the non-volatile approach for POA emission contribute a major portion of the overprediction in winter. Meanwhile, the forecasting system may be improved through updating the emissions inventory used (i.e., NEI 2014) to NEI 2016v2 or NEI 2017, which are more representative of the year of 2019 in the next development of next-generation NAQFC.

Categorical evaluation indicates that the GFSv15CMAQv5.0.2 can capture well the air quality classification of the Moderate category described by the AQI. However, the categorical performance is poorer for $\mathrm{PM}_{2.5}$ at the Unhealthy for sensitive groups threshold due mainly to the significant overprediction during the cooler months. Regionspecific evaluation further discusses the biases and underlying causes in the 10 U.S. EPA defined regions in CONUS. An update from CMAQv5.0.2 to v5.3.1 is expected to alleviate potential errors in missing sources and mechanisms for SOA formation. The variations of performance between $\mathrm{O}_{3}$ and non- $\mathrm{O}_{3}$ seasons, as well as during the daytime and nighttime, indicate that further studies need to be conducted to improve boundary layer mixing processes within GFSv15CMAQv5.0.2. The varied region-specific performance indicates that improvements, such as bias corrections, should be considered individually from region to region in the subsequent development of the next-generation NAQFC.

We have used bias analyses in this work to identify several areas of weakness in the GFSv15-CMAQv5.0.2 system for further improvement and development of next-generation NAQFC. The ability of FV3-based GFS in driving the realtime air quality forecasting is demonstrated. Further studies are still needed to improve the accuracy in meteorological forecast, the emissions, the aerosol chemistry, and the boundary layer mixing for the future GFS-FV3-CMAQ system.

Code and data availability. The documentation and source code of CMAQv5.0.2 are available at https://doi.org/10.5281/zenodo. 1079898 (United States Environmental Protection Agency, 2014). The GFS forecast inputs in binary (NEMSIO) format and the coupler used in this study for the GFSv15-CMAQv5.0.2 system are available upon request. The AIRNow data is available for download through the US EPA AirData website (https://www.epa.gov/airdata, US EPA, 2020a). The CASTNET data are available for download from https://www.epa.gov/castnet (US EPA, 2020b). The METAR data are available for download from https://madis.ncep.noaa.gov (NOAA, 2020a). The GPCP data are available through the NOAA website (https://www.ncei.noaa. gov/data/global-precipitation-climatology-project-gpcp-monthly,
NOAA 2020b). The CCPA precipitation data are available upon request. The MODIS_MOD04 dataset is available at https://doi.org/10.5067/MODIS/MOD04_L2.006 (Levy and Hsu, 2015). The data processing and analysis scripts are available upon request.

Supplement. The supplement related to this article is available online at: https://doi.org/10.5194/gmd-14-3969-2021-supplement.

Author contributions. YZ and DT defined the scope and focus of the paper and designed the model simulations. XC and YZ developed the paper outline and structure. PL, JH, YT, and JM performed the forecast simulations. YT generated the emissions and PCC generated the lateral boundary conditions for the model simulations. $\mathrm{XC}$ performed the model evaluation and drafted the paper. $\mathrm{XC}$ and KW developed postprocessing and statistical scripts. HOTP, BNM, and DK assisted in the analysis of region-specific biases. YZ, HOTP, DK, BNM, JH, PCC, PL, DT, and KW reviewed the paper.

Competing interests. The authors declare that they have no conflict of interest.

Disclaimer. The scientific results and conclusions, as well as any views or opinions expressed herein, are those of the author(s) and do not necessarily reflect the views of NOAA or the Department of Commerce. The views expressed in this document are solely those of the authors and do not necessarily reflect those of the U.S. EPA. EPA does not endorse any products or commercial services mentioned in this publication.

Acknowledgements. Thanks to Fanglin Yang for providing information regarding GFSv15. High-performance computing at Northeastern University was supported by the Stampede XSEDE highperformance computing support under NSF ACI 1053575.

Financial support. This research has been supported by the NOAA Office of Weather and Air Quality (grant no. NA19OAR4590084 at North Carolina State University, no. NA20OAR4590259 at Northeastern University, and no. NA19OAR4590085 at George Mason University).

Review statement. This paper was edited by Jason Williams and reviewed by two anonymous referees.

\section{References}

Adams, J. W. and Cox, R. A.: Halogen chemistry of the marine boundary layer, J. Phys. IV, 12, 105-124, https://doi.org/10.1051/jp4:20020455, 2002. 
Appel, K. W., Pouliot, G. A., Simon, H., Sarwar, G., Pye, H. O. T., Napelenok, S. L., Akhtar, F., and Roselle, S. J.: Evaluation of dust and trace metal estimates from the Community Multiscale Air Quality (CMAQ) model version 5.0, Geosci. Model Dev., 6, 883-899, https://doi.org/10.5194/gmd-6-883-2013, 2013.

Appel, K. W., Bash, J. O., Fahey, K. M., Foley, K. M., Gilliam, R. C., Hogrefe, C., Hutzell, W. T., Kang, D., Mathur, R., Murphy, B. N., Napelenok, S. L., Nolte, C. G., Pleim, J. E., Pouliot, G. A., Pye, H. O. T., Ran, L., Roselle, S. J., Sarwar, G., Schwede, D. B., Sidi, F. I., Spero, T. L., and Wong, D. C.: The Community Multiscale Air Quality (CMAQ) Model Versions 5.3 and 5.3.1: System Updates and Evaluation, Geosci. Model Dev. Discuss. [preprint], https://doi.org/10.5194/gmd-2020-345, accepted, 2021.

Arakawa, A. and Lamb, V. R.: Computational design of the basic dynamical processes of the UCLA General Circulation Model, Methods Comput. Phys., 17, 173-265, available at: http://ci.nii. ac.jp/naid/10012003123/en/ (last access: 22 May 2020), 1977.

Arakawa, A. and Schubert, W. H.: Interaction of a Cumulus Cloud Ensemble with the Large-Scale Environment, Part I, J. Atmos. Sci., 31, 674-701, https://doi.org/10.1175/15200469(1974)031<0674:IOACCE>2.0.CO;2, 1974.

Barnes, L. R., Schultz, D. M., Gruntfest, E. C., Hayden, M. H., and Benight, C. C.: Corrigendum: False alarm rate or false alarm ratio?, Weather Forecast., 24, 1452-1454, https://doi.org/10.1175/2009WAF2222300.1, 2009.

Binkowski, F. S., Arunachalam, S., Adelman, Z., and Pinto, J. P.: Examining photolysis rates with a prototype online photolysis module in CMAQ, J. Appl. Meteorol. Clim., 46, 1252-1256, https://doi.org/10.1175/JAM2531.1, 2007.

Black, T. L.: The New NMC Mesoscale Eta Model: Description and Forecast Examples, Weather Forecast., $\quad 9, \quad 265-278, \quad$ https://doi.org/10.1175/15200434(1994)009<0265:TNNMEM>2.0.CO;2, 1994.

Bloomer, B. J., Stehr, J. W., Piety, C. A., Salawitch, R. J., and Dickerson, R. R.: Observed relationships of ozone air pollution with temperature and emissions, Geophys. Res. Lett., 36, L09803, https://doi.org/10.1029/2009GL037308, 2009.

Byun, D. and Schere, K. L.: Review of the governing equations, computational algorithms, and other components of the models3 community multiscale air quality (CMAQ) modeling system, Appl. Mech. Rev., 59, 51-77, https://doi.org/10.1115/1.2128636, 2006.

Campbell, P., Tang, Y., Lee, P., Baker, B., Tong, D., Saylor, R., Stein, A., Huang, J., Huang, H., Strobach, E., McQueen, J., Stajner, I., Koch, D., Tirado-Delgado, J., and Jung, Y.: An Improved National Air Quality Forecasting Capability Using the NOAA Global Forecast System. Part I: Model Development and Community Application, in: the 19th CMAS Conference, Virtual, 2630 October 2020, 2020.

Carlton, A. G., Bhave, P. V., Napelenok, S. L., Edney, E. O., Sarwar, G., Pinder, R. W., Pouliot, G. A., and Houyoux, M.: Model representation of secondary organic aerosol in CMAQv4.7, Environ. Sci. Technol., 44, 8553-8560, https://doi.org/10.1021/es100636q, 2010.

Carlton, A. G., Pye, H. O. T., Baker, K. R., and Hennigan, C. J.: Additional Benefits of Federal Air-Quality Rules: Model Estimates of Controllable Biogenic Secondary Organic Aerosol, Environ. Sci. Technol., 52, 9254-9265, https://doi.org/10.1021/acs.est.8b01869, 2018.
Chen, F., Janjić, Z., and Mitchell, K.: Impact of atmospheric surface-layer parameterizations in the new land-surface scheme of the NCEP mesoscale Eta model, Bound.-Lay. Meteorol., 85, 391-421, https://doi.org/10.1023/A:1000531001463, 1997.

Chuang, M. T., Zhang, Y., and Kang, D.: Application of WRF/Chem-MADRID for real-time air quality forecasting over the Southeastern United States, Atmos. Environ., 45, 6241-6250, https://doi.org/10.1016/j.atmosenv.2011.06.071, 2011.

Clough, S. A., Shephard, M. W., Mlawer, E. J., Delamere, J. S., Iacono, M. J., Cady-Pereira, K., Boukabara, S., and Brown, P. D.: Atmospheric radiative transfer modeling: A summary of the AER codes, J. Quant. Spectrosc. Ra., 91, 233-244, https://doi.org/10.1016/j.jqsrt.2004.05.058, 2005.

Cuchiara, G. C., Li, X., Carvalho, J., and Rappenglück, B.: Intercomparison of planetary boundary layer parameterization and its impacts on surface ozone concentration in the WRF/Chem model for a case study in houston/texas, Atmos. Environ., 96, 175-185, https://doi.org/10.1016/j.atmosenv.2014.07.013, 2014.

D’Allura, A., Costa, M. P., and Silibello, C.: Qualearia: European and national scale air quality forecast system performance evaluation, Int. J. Environ. Pollut., 64, 110-124, https://doi.org/10.1504/IJEP.2018.099152, 2018.

Eder, B., Kang, D., Mathur, R., Yu, S., and Schere, K.: An operational evaluation of the Eta-CMAQ air quality forecast model, Atmos. Environ., 40, 4894-4905, https://doi.org/10.1016/j.atmosenv.2005.12.062, 2006.

Eder, B., Kang, D., Mathur, R., Pleim, J., Yu, S., Otte, T., and Pouliot, G.: A performance evaluation of the National Air Quality Forecast Capability for the summer of 2007, Atmos. Environ., 43, 2312-2320, https://doi.org/10.1016/j.atmosenv.2009.01.033, 2009.

Emery, C., Jung, J., Koo, B., and Yarwood, G.: Improvements to CAMx Snow Cover Treatments and Carbon Bond Chemical Mechanism for Winter Ozone, Final report for Utah DAQ, project UDAQ PO $48052000000001,2015$.

Emery, C., Liu, Z., Russell, A. G., Odman, M. T., Yarwood, G., and Kumar, N.: Recommendations on statistics and benchmarks to assess photochemical model performance, J. Air Waste Manage., 67, 582-598, https://doi.org/10.1080/10962247.2016.1265027, 2017.

Foster, K. L., Plastridge, R. A., Bottenheim, J. W., Shepson, P. B., Finlayson-Pitts, B. J., and Spicer, C. W.: The role of $\mathrm{Br}_{2}$ and $\mathrm{BrCl}$ in surface ozone destruction at polar sunrise, Science, 291, 471-474, https://doi.org/10.1126/science.291.5503.471, 2001.

Gantt, B., Sarwar, G., Xing, J., Simon, H., Schwede, D., Hutzell, W. T., Mathur, R., and Saiz-Lopez, A.: The Impact of Iodide-Mediated Ozone Deposition and Halogen Chemistry on Surface Ozone Concentrations Across the Continental United States, Environ. Sci. Technol., 51, 1458-1466, https://doi.org/10.1021/acs.est.6b03556, 2017.

Grell, G. A.: Prognostic Evaluation of Assumptions Used by Cumulus Parameterizations, Mon. Weather Rev., 121, 764-787, https://doi.org/10.1175/15200493(1993)121<0764:PEOAUB>2.0.CO;2, 1993.

Ha, S., Liu, Z., Sun, W., Lee, Y., and Chang, L.: Improving air quality forecasting with the assimilation of GOCI aerosol optical depth (AOD) retrievals during the KORUS-AQ period, Atmos. Chem. Phys., 20, 6015-6036, https://doi.org/10.5194/acp20-6015-2020, 2020. 
He, J., He, R., and Zhang, Y.: Impacts of Air-sea Interactions on Regional Air Quality Predictions Using a Coupled Atmosphereocean Model in Southeastern U.S., Aerosol Air Qual. Res., 18, 1044-1067, https://doi.org/10.4209/aaqr.2016.12.0570, 2018.

He, P., Bian, L., Zheng, X., Yu, J., Sun, C., Ye, P., and Xie, Z.: Observation of surface ozone in the marine boundary layer along a cruise through the Arctic Ocean: From offshore to remote, Atmos. Res., 169, 191-198, https://doi.org/10.1016/j.atmosres.2015.10.009, 2016.

Hou, D., Charles, M., Luo, Y., Toth, Z., Zhu, Y., Krzysztofowicz, R., Lin, Y., Xie, P., Seo, D. J., Pena, M., and Cui, B.: Climatologycalibrated precipitation analysis at fine scales: Statistical adjustment of stage IV toward CPC gauge-based analysis, J. Hydrometeorol., 15, 2542-2557, https://doi.org/10.1175/JHM-D11-0140.1, 2014.

$\mathrm{Hu}, \mathrm{X} . \mathrm{M}$., Klein, P. M., and Xue, M.: Evaluation of the updated YSU planetary boundary layer scheme within WRF for wind resource and air quality assessments, J. Geophys. Res.-Atmos., 118, 10490-10505, https://doi.org/10.1002/jgrd.50823, 2013.

Huang, J., McQueen, J., Wilczak, J., Djalalova, I., Stajner, I., Shafran, P., Allured, D., Lee, P., Pan, L., Tong, D., Huang, H.-C., DiMego, G., Upadhayay, S., and Delle Monache, L.: Improving NOAA NAQFC PM 2.5 Predictions with a Bias Correction Approach, Weather Forecast., 32, 407-421, https://doi.org/10.1175/WAF-D-16-0118.1, 2017.

Huang, J., McQueen, J., Shafran, P., Huang, H., Kain, J., Tang, Y., Lee, P., Stajner, I., and Tirado-Delgado, J.: Development and evaluation of offline coupling of FV3-based GFS with CMAQ at NOAA, in: the 17th CMAS Conference, UNC-Chapel Hill, NC, 22-24 October 2018, 2018.

Huang, J., McQueen, J., Yang, B., Shafran, P., Pan, L., Huang, H., Bhattacharjee, P., Tang, Y., Campbell, P., Tong, D., Lee, P., Stajner, I., Kain, J., Tirado-Delgado, J., and Koch, D.: Impact of global scale FV3 versus regional scale NAM meteorological driver model predictions on regional air quality forecasting, in: The 100th AGU Fall Meeting, San Francisco, CA, 9-13 December 2019, 2019.

Iacono, M. J., Mlawer, E. J., Clough, S. A., and Morcrette, J.-J.: Impact of an improved longwave radiation model, RRTM, on the energy budget and thermodynamic properties of the NCAR community climate model, CCM3, J. Geophys. Res.-Atmos., 105, 14873-14890, https://doi.org/10.1029/2000JD900091, 2000.

Kang, D., Eder, B. K., Stein, A. F., Grell, G. A., Peckham, S. E., and Mc Henry, J.: The New England Air Quality Forecasting Pilot Program: Development of an Evaluation Protocol and Performance Benchmark, J. Air Waste Manage., 55, 1782-1796, https://doi.org/10.1080/10473289.2005.10464775, 2005.

Kang, D., Mathur, R., Rao, S. T., and Yu, S.: Bias adjustment techniques for improving ozone air quality forecasts, J. Geophys. Res., 113, D23308, https://doi.org/10.1029/2008JD010151, 2008.

Kang, D., Mathur, R., and Trivikrama Rao, S.: Assessment of bias-adjusted $\mathrm{PM}_{2.5}$ air quality forecasts over the continental United States during 2007, Geosci. Model Dev., 3, 309-320, https://doi.org/10.5194/gmd-3-309-2010, 2010a.

Kang, D., Mathur, R., and Trivikrama Rao, S.: Real-time bias-adjusted $\mathrm{O}_{3}$ and $\mathrm{PM}_{2.5}$ air quality index forecasts and their performance evaluations over the conti- nental United States, Atmos. Environ., 44, 2203-2212, https://doi.org/10.1016/j.atmosenv.2010.03.017, 2010 b.

Kang, D., Foley, K. M., Mathur, R., Roselle, S. J., Pickering, K. E., and Allen, D. J.: Simulating lightning NO production in CMAQv5.2: performance evaluations, Geosci. Model Dev., 12, 4409-4424, https://doi.org/10.5194/gmd-12-4409-2019, 2019a.

Kang, D., Pickering, K. E., Allen, D. J., Foley, K. M., Wong, D. C., Mathur, R., and Roselle, S. J.: Simulating lightning NO production in CMAQv5.2: evolution of scientific updates, Geosci. Model Dev., 12, 3071-3083, https://doi.org/10.5194/gmd-123071-2019, 2019b.

Lee, P., Ngan, F., Kim, H., Tong, D., Tang, Y., Chai, T., Saylor, R., Stein, A., Byun, D., Tsidulko, M., McQueen, J., and Stajner, I.: Incremental Development of Air Quality Forecasting System with Off-Line/On-Line Capability: Coupling CMAQ to NCEP National Mesoscale Model, in: Air Pollution Modeling and its Application XXI, Springer, Dordrecht, 187-192, 2011.

Lee, P., McQueen, J., Stajner, I., Huang, J., Pan, L., Tong, D., Kim, H., Tang, Y., Kondragunta, S., Ruminski, M., Lu, S., Rogers, E., Saylor, R., Shafran, P., Huang, H.-C., Gorline, J., Upadhayay, S., and Artz, R.: NAQFC Developmental Forecast Guidance for Fine Particulate Matter $\left(\mathrm{PM}_{2.5}\right)$, Weather Forecast., 32, 343-360, https://doi.org/10.1175/waf-d-15-0163.1, 2017.

Levy, R. and Hsu, C.: MODIS Atmosphere L2 Aerosol Product, NASA MODIS Adaptive Processing System, Goddard Space Flight Center, USA, https://doi.org/10.5067/MODIS/MOD04_L2.006, 2015.

Liu, Y., Fan, Q., Chen, X., Zhao, J., Ling, Z., Hong, Y., Li, W., Chen, X., Wang, M., and Wei, X.: Modeling the impact of chlorine emissions from coal combustion and prescribed waste incineration on tropospheric ozone formation in China, Atmos. Chem. Phys., 18, 2709-2724, https://doi.org/10.5194/acp-182709-2018, 2018.

Lu, C.-H., da Silva, A., Wang, J., Moorthi, S., Chin, M., Colarco, P., Tang, Y., Bhattacharjee, P. S., Chen, S.-P., Chuang, H.-Y., Juang, H.-M. H., McQueen, J., and Iredell, M.: The implementation of NEMS GFS Aerosol Component (NGAC) Version 1.0 for global dust forecasting at NOAA/NCEP, Geosci. Model Dev., 9, 19051919, https://doi.org/10.5194/gmd-9-1905-2016, 2016.

Luecken, D. J., Yarwood, G., and Hutzell, W. T.: Multipollutant modeling of ozone, reactive nitrogen and HAPs across the continental US with CMAQ-CB6, Atmos. Environ., 201, 62-72, https://doi.org/10.1016/j.atmosenv.2018.11.060, 2019.

Lyu, B., Zhang, Y., and $\mathrm{Hu}$, Y.: Improving $\mathrm{PM}_{2.5}$ Air Quality Model Forecasts in China Using a BiasCorrection Framework, Atmosphere-Basel, 8, 147, https://doi.org/10.3390/atmos8080147, 2017.

Mathur, R., Yu, S., Kang, D., and Schere, K. L.: Assessment of the wintertime performance of developmental particulate matter forecasts with the Eta-Community Multiscale Air Quality modeling system, J. Geophys. Res., 113, D02303, https://doi.org/10.1029/2007JD008580, 2008.

McHenry, J. N., Ryan, W. F., Seamn, N. L., Coats, C. J., Pudykiewicz, J., Arunachalam, S., and Vukovich, J. M.: A realtime eulerian photochemical model forecast system, B. Am. Meteorol. Soc., 85, 525-548, https://doi.org/10.1175/BAMS-85-4525, 2004.

McKeen, S., Wilczak, J., Grell, G., Djalalova, I., Peckham, S., Hsie, E.-Y., Gong, W., Bouchet, V., Menard, S., Moffet, R., 
McHenry, J., McQueen, J., Tang, Y., Carmichael, G. R., Pagowski, M., Chan, A., Dye, T., Frost, G., Lee, P., and Mathur, R.: Assessment of an ensemble of seven realtime ozone forecasts over eastern North America during the summer of 2004, J. Geophys. Res., 110, D21307, https://doi.org/10.1029/2005JD005858, 2005.

McKeen, S., Chung, S. H., Wilczak, J., Grell, G., Djalalova, I., Peckham, S., Gong, W., Bouchet, V., Moffet, R., Tang, Y., Carmichael, G. R., Mathur, R., and Yu, S.: Evaluation of several $\mathrm{PM}_{2.5}$ forecast models using data collected during the ICARTT/NEAQS 2004 field study, J. Geophys. Res.-Atmos., 112, D10S20, https://doi.org/10.1029/2006JD007608, 2007.

McKeen, S., Grell, G., Peckham, S., Wilczak, J., Djalalova, I., Hsie, E.-Y., Frost, G., Peischl, J., Schwarz, J., Spackman, R., Holloway, J., de Gouw, J., Warneke, C., Gong, W., Bouchet, V., Gaudreault, S., Racine, J., McHenry, J., McQueen, J., Lee, P., Tang, Y., Carmichael, G. R., and Mathur, R.: An evaluation of real-time air quality forecasts and their urban emissions over eastern Texas during the summer of 2006 Second Texas Air Quality Study field study, J. Geophys. Res., 114, D00F11, https://doi.org/10.1029/2008JD011697, 2009.

Mlawer, E. J., Taubman, S. J., Brown, P. D., Iacono, M. J., and Clough, S. A.: Radiative transfer for inhomogeneous atmospheres: RRTM, a validated correlated-k model for the longwave, J. Geophys. Res.-Atmos., 102, 16663-16682, https://doi.org/10.1029/97jd00237, 1997.

Moran, M. D., Lupu, A., Zhang, J., Savic-Jovcic, V., and Gravel, S.: A comprehensive performance evaluation of the next generation of the Canadian operational regional air quality deterministic prediction system, in: Air Pollution Modeling and its Application XXV, edited by: Mensink, C. and Kallos, G., Springer Proceedings in Complexity, Springer, Cham, https://doi.org/10.1007/978-3-319-57645-9_12, pp. 7581, 2018.

Murphy, B. N., Woody, M. C., Jimenez, J. L., Carlton, A. M. G., Hayes, P. L., Liu, S., Ng, N. L., Russell, L. M., Setyan, A., Xu, L., Young, J., Zaveri, R. A., Zhang, Q., and Pye, H. O. T.: Semivolatile POA and parameterized total combustion SOA in CMAQv5.2: impacts on source strength and partitioning, Atmos. Chem. Phys., 17, 11107-11133, https://doi.org/10.5194/acp-1711107-2017, 2017.

National Centers for Environmental Prediction: The Global Forecast System (GFS) - Global Spectral Model (GSM), available at: https://www.emc.ncep.noaa.gov/emc/pages/numerical_forecast_ systems/gfs/documentation.php (last access: 22 May 2020), 2019a.

National Centers for Environmental Prediction: FV3: The GFDL Finite-Volume Cubed-Sphere Dynamical Core, available at: https://vlab.ncep.noaa.gov/web/fv3gfs (last access: 22 May 2020), 2019b.

National Oceanic and Atmospheric Administration: Meteorological Assimilation Data Ingest System (MADIS), available at: https: //madis.ncep.noaa.gov, last access: 28 May 2020a.

National Oceanic and Atmospheric Administration: Global Precipitation Climatology Project (GPCP) monthly product, available at: https://www.ncei.noaa.gov/data/ global-precipitation-climatology-project-gpcp-monthly, last accessed: 21 January 2020 b.
Oliveri Conti, G., Heibati, B., Kloog, I., Fiore, M., and Ferrante, M.: A review of AirQ Models and their applications for forecasting the air pollution health outcomes, Environ. Sci. Pollut. R., 24, 6426-6445, https://doi.org/10.1007/s11356-016-8180-1, 2017.

Otte, T. L., Pouliot, G., Pleim, J. E., Young, J. O., Schere, K. L., Wong, D. C., Lee, P. C. S., Tsidulko, M., McQueen, J. T., Davidson, P., Mathur, R., Chuang, H.-Y., DiMego, G., and Seaman, N. L.: Linking the Eta Model with the Community Multiscale Air Quality (CMAQ) Modeling System to Build a National Air Quality Forecasting System, Weather Forecast., 20, 367-384, https://doi.org/10.1175/WAF855.1, 2005.

Park, R. J., Hong, S. K., Kwon, H.-A., Kim, S., Guenther, A., Woo, J.-H., and Loughner, C. P.: An evaluation of ozone dry deposition simulations in East Asia, Atmos. Chem. Phys., 14, 7929-7940, https://doi.org/10.5194/acp-14-7929-2014, 2014.

Peng, Z., Lei, L., Liu, Z., Sun, J., Ding, A., Ban, J., Chen, D., Kou, $\mathrm{X}$., and Chu, K.: The impact of multi-species surface chemical observation assimilation on air quality forecasts in China, Atmos. Chem. Phys., 18, 17387-17404, https://doi.org/10.5194/acp-1817387-2018, 2018.

Pleim, J., Gilliam, R., Appel, W., and Ran, L.: Recent Advances in Modeling of the Atmospheric Boundary Layer and Land Surface in the Coupled WRF-CMAQ Model BT - Air Pollution Modeling and its Application XXIV, in: Air Pollution Modeling and its Application XXIV, edited by: Steyn, D. G. and Chaumerliac, N., Springer International Publishing, Cham, 391-396, 2016.

Pleim, J. E., Bash, J. O., Walker, J. T., and Cooter, E. J.: Development and evaluation of an ammonia bidirectional flux parameterization for air quality models, J. Geophys. Res.-Atmos., 118, 3794-3806, https://doi.org/10.1002/jgrd.50262, 2013.

Pleim, J. E., Ran, L., Appel, W., Shephard, M. W., and CadyPereira, K.: New Bidirectional Ammonia Flux Model in an Air Quality Model Coupled With an Agricultural Model, J. Adv. Model. Earth Sy., 11, 2934-2957, https://doi.org/10.1029/2019MS001728, 2019.

Podrascanin, Z.: Setting-up a Real-Time Air Quality Forecasting system for Serbia: a WRF-Chem feasibility study with different horizontal resolutions and emission inventories, Environ. Sci. Pollut. R., 26, 17066-17079, https://doi.org/10.1007/s11356019-05140-y, 2019.

Putman, W. M. and Lin, S. J.: Finite-volume transport on various cubed-sphere grids, J. Comput. Phys., 227, 55-78, https://doi.org/10.1016/j.jcp.2007.07.022, 2007.

Pye, H. O. T., Pinder, R. W., Piletic, I. R., Xie, Y., Capps, S. L., Lin, Y. H., Surratt, J. D., Zhang, Z. F., Gold, A., Luecken, D. J., Hutzell, W. T., Jaoui, M., Offenberg, J. H., Kleindienst, T. E., Lewandowski, M., and Edney, E. O.: Epoxide Pathways Improve Model Predictions of Isoprene Markers and Reveal Key Role of Acidity in Aerosol Formation, Environ. Sci. Technol. 47, 11056-11064, https://doi.org/10.1021/es402106h, 2013.

Pye, H. O. T., Luecken, D. J., Xu, L., Boyd, C. M., Ng, N. L., Baker, K. R., Ayres, B. R., Bash, J. O., Baumann, K., Carter, W. P., Edgerton, E., Fry, J. L., Hutzell, W. T., Schwede, D. B., and Shepson, P. B.: Modeling the Current and Future Roles of Particulate Organic Nitrates in the Southeastern United States, Environ. Sci. Technol., 49, 14195-14203, https://doi.org/10.1021/acs.est.5b03738, 2015.

Pye, H. O. T., Murphy, B. N., Xu, L., Ng, N. L., Carlton, A. G., Guo, H., Weber, R., Vasilakos, P., Appel, K. W., Budisulistior- 
ini, S. H., Surratt, J. D., Nenes, A., Hu, W., Jimenez, J. L., Isaacman-VanWertz, G., Misztal, P. K., and Goldstein, A. H.: On the implications of aerosol liquid water and phase separation for organic aerosol mass, Atmos. Chem. Phys., 17, 343-369, https://doi.org/10.5194/acp-17-343-2017, 2017.

Pye, H. O. T., Zuend, A., Fry, J. L., Isaacman-VanWertz, G., Capps, S. L., Appel, K. W., Foroutan, H., Xu, L., Ng, N. L., and Goldstein, A. H.: Coupling of organic and inorganic aerosol systems and the effect on gas-particle partitioning in the southeastern US, Atmos. Chem. Phys., 18, 357-370, https://doi.org/10.5194/acp18-357-2018, 2018.

Pye, H. O. T., D’Ambro, E. L., Lee, B. H., Schobesberger, S., Takeuchi, M., Zhao, Y., Lopez-Hilfiker, F., Liu, J., Shilling, J. E., Xing, J., Mathur, R., Middlebrook, A. M., Liao, J., Welti, A., Graus, M., Warneke, C., de Gouw, J. A., Holloway, J. S., Ryerson, T. B., Pollack, I. B., and Thornton, J. A.: Anthropogenic enhancements to production of highly oxygenated molecules from autoxidation, P. Natl. Acad. Sci. USA, 116, 6641-6646, https://doi.org/10.1073/pnas.1810774116, 2019.

Rasmussen, D. J., Fiore, A. M., Naik, V., Horowitz, L. W., McGinnis, S. J., and Schultz, M. G.: Surface ozone-temperature relationships in the eastern US: A monthly climatology for evaluating chemistry-climate models, Atmos. Environ., 47, 142-153, https://doi.org/10.1016/j.atmosenv.2011.11.021, 2012.

Russell, M., Hakami, A., Makar, P. A., Akingunola, A., Zhang, J., Moran, M. D., and Zheng, Q.: An evaluation of the efficacy of very high resolution air-quality modelling over the Athabasca oil sands region, Alberta, Canada, Atmos. Chem. Phys., 19, 43934417, https://doi.org/10.5194/acp-19-4393-2019, 2019.

Ryan, W. F.: The air quality forecast rote: Recent changes and future challenges, J. Air Waste Manage., 66, 576-596, https://doi.org/10.1080/10962247.2016.1151469, 2016.

Sarwar, G., Fahey, K., Napelenok, S., Roselle, S., and Mathur, R.: Examining the impact of CMAQ model updates on aerosol sulfate predictions, in: the 10th Annual CMAS Models-3 User's Conference, Chapel Hill, NC, October 2011, 2011.

Sarwar, G., Simon, H., Bhave, P., and Yarwood, G.: Examining the impact of heterogeneous nitryl chloride production on air quality across the United States, Atmos. Chem. Phys., 12, 6455-6473, https://doi.org/10.5194/acp-12-6455-2012, 2012.

Sarwar, G., Gantt, B., Schwede, D., Foley, K., Mathur, R., and Saiz-Lopez, A.: Impact of Enhanced Ozone Deposition and Halogen Chemistry on Tropospheric Ozone over the Northern Hemisphere, Environ. Sci. Technol., 49, 9203-9211, https://doi.org/10.1021/acs.est.5b01657, 2015.

Schwede, D., Pouliot, G., and Pierce, T.: Changes to the Biogenic Emissions Inventory System Version 3 (BEIS3), available at: https://www.cmascenter.org/conference/2005/abstracts/ 2_7.pdf (last access: 28 June 2020), 2005.

Shen, L., Mickley, L. J., and Gilleland, E.: Impact of increasing heat waves on U.S. ozone episodes in the 2050s: Results from a multimodel analysis using extreme value theory, Geophys. Res. Lett., 43, 4017-4025, https://doi.org/10.1002/2016GL068432, 2016.

Sillman, S.: The relation between ozone, $\mathrm{NO}_{x}$ and hydrocarbons in urban and polluted rural environments, Atmos. Environ., 33, 1821-1845, https://doi.org/10.1016/S1352-2310(98)003458,1999 .

Sillman, S. and Samson, P. J.: Impact of temperature on oxidant photochemistry in urban polluted rural and re- mote environments, J. Geophys. Res., 100, 11497-11508, https://doi.org/10.1029/94jd02146, 1995.

Simon, H. and Bhave, P. V.: Simulating the degree of oxidation in atmospheric organic particles, Environ. Sci. Technol., 46, 331339. https://doi.org/10.1021/es202361w, 2012.

Spiridonov, V., Jakimovski, B., Spiridonova, I., and Pereira, G.: Development of air quality forecasting system in Macedonia, based on WRF-Chem model, Air Qual. Atmos. Hlth., 12, 825-836, https://doi.org/10.1007/s11869-019-00698-5, 2019.

Stajner, I., Davidson, P., Byun, D., McQueen, J., Draxler, R., Dickerson, P., and Meagher, J.: US National Air Quality Forecast Capability: Expanding Coverage to Include Particulate Matter, in: Air Pollution Modeling and its Application XXI, Springer, Dordrecht, 379-384, 2011.

Stein, A. F., Lamb, D., and Draxler, R. R.: Incorporation of detailed chemistry into a three-dimensional Lagrangian-Eulerian hybrid model: Application to regional tropospheric ozone, Atmos. Environ., 34, 4361-4372, https://doi.org/10.1016/S13522310(00)00204-1, 2000.

Stortini, M., Arvani, B., and Deserti, M.: Operational forecast and daily assessment of the air quality in Italy: A copernicus-CAMS downstream service, Atmosphere-Basel, 11, 447, https://doi.org/10.3390/ATMOS11050447, 2020.

Struzewska, J., Kaminski, J. W., and Jefimow, M.: Application of model output statistics to the GEM-AQ high resolution air quality forecast, Atmos. Res., 181, 186-199, https://doi.org/10.1016/j.atmosres.2016.06.012, 2016.

Tang, Y., Chai, T., Pan, L., Lee, P., Tong, D., Kim, H.-C., and Chen, W.: Using optimal interpolation to assimilate surface measurements and satellite $\mathrm{AOD}$ for ozone and $\mathrm{PM}_{2.5}$ : A case study for July 2011, J. Air Waste Manage., 65, 1206-1216, https://doi.org/10.1080/10962247.2015.1062439, 2015.

Tang, Y., Pagowski, M., Chai, T., Pan, L., Lee, P., Baker, B., Kumar, R., Delle Monache, L., Tong, D., and Kim, H.-C.: A case study of aerosol data assimilation with the Community Multi-scale Air Quality Model over the contiguous United States using 3DVar and optimal interpolation methods, Geosci. Model Dev., 10, 4743-4758, https://doi.org/10.5194/gmd-10-4743-2017, 2017.

Taylor, K. E.: Summarizing multiple aspects of model performance in a single diagram, J. Geophys. Res.-Atmos., 106, 7183-7192, https://doi.org/10.1029/2000JD900719, 2001.

Tegtmeier, S., Ziska, F., Pisso, I., Quack, B., Velders, G. J. M., Yang, X., and Krüger, K.: Oceanic bromoform emissions weighted by their ozone depletion potential, Atmos. Chem. Phys., 15, 1364713663, https://doi.org/10.5194/acp-15-13647-2015, 2015.

United States Environmental Protection Agency: CMAQv5.0.2 (Version 5.0.2), Zenodo, https://doi.org/10.5281/zenodo.1079898, 2014.

United States Environmental Protection Agency: Air Quality System Data Mart [internet database], available at: https://www.epa. gov/airdata, last access: 2 June 2020a.

United States Environmental Protection Agency: Clean Air Markets Division Clean Air Status and Trends Network (CASTNET), available at: https://www.epa.gov/castnet, last access: 10 March 2020b.

Wang, K., Yahya, K., Zhang, Y., Hogrefe, C., Pouliot, G., Knote, C., Hodzic, A., San Jose, R., Perez, J. L., Jiménez-Guerrero, P., Baro, R., Makar, P., and Bennartz, R.: A multi-model assessment for the 2006 and 2010 simulations under the Air Qual- 
ity Model Evaluation International Initiative (AQMEII) Phase 2 over North America: Part II. Evaluation of column variable predictions using satellite data, Atmos. Environ., 115, 587-603, https://doi.org/10.1016/j.atmosenv.2014.07.044, 2015.

Watanabe, K.: Measurements of ozone concentrations on a commercial vessel in the marine boundary layer over the northern North Pacific Ocean, J. Geophys. Res., 110, D11310, https://doi.org/10.1029/2004JD005514, 2005.

Wu, Z., Schwede, D. B., Vet, R., Walker, J. T., Shaw, M., Staebler, R., and Zhang, L.: Evaluation and Intercomparison of Five North American Dry Deposition Algorithms at a Mixed Forest Site, J. Adv. Model. Earth Sy., 10, 1571-1586, https://doi.org/10.1029/2017MS001231, 2018.

Xu, L., Pye, H. O. T., He, J., Chen, Y., Murphy, B. N., and Ng, N. L.: Experimental and model estimates of the contributions from biogenic monoterpenes and sesquiterpenes to secondary organic aerosol in the southeastern United States, Atmos. Chem. Phys., 18, 12613-12637, https://doi.org/10.5194/acp-18-126132018, 2018.

Yang, F.: GDAS/GFS V15.0.0 Upgrades for Q2FY2019, available at: https://www.emc.ncep.noaa.gov/users/Alicia.Bentley/ fv3gfs/updates/EMC_CCB_FV3GFS_9-24-18.pdf (last access: 22 May 2020), 2019.

Yang, X., Blechschmidt, A.-M., Bognar, K., McClure-Begley, A., Morris, S., Petropavlovskikh, I., Richter, A., Skov, H., Strong, K., Tarasick, D. W., Uttal, T., Vestenius, M., and Zhao, X.: Pan-Arctic surface ozone: modelling vs. measurements, Atmos. Chem. Phys., 20, 15937-15967, https://doi.org/10.5194/acp-2015937-2020, 2020.

Yarwood, G., Rao, S., Yocke, M., and Whitten, G.: Updates to the Carbon Bond Chemical Mechanism: CB05. Final Report to the US EPA, RT-0400675. Yocke and Company, Novato, CA, 2005.

Yarwood, G., Whitten, G. Z., Jung, J., Heo, G., and Allen, D. T.: Development, evaluation and testing of version 6 of the Carbon Bond chemical mechanism (CB6), Final report to the Texas Commission on Environmental Quality, Work Order No. 582-784005-FY10-26, 2010.

Žabkar, R., Honzak, L., Skok, G., Forkel, R., Rakovec, J., Ceglar, A., and Žagar, N.: Evaluation of the high resolution WRFChem (v3.4.1) air quality forecast and its comparison with statistical ozone predictions, Geosci. Model Dev., 8, 2119-2137, https://doi.org/10.5194/gmd-8-2119-2015, 2015.

Zhang, C., Xue, M., Supinie, T. A., Kong, F., Snook, N., Thomas, K. W., Brewster, K., Jung, Y., Harris, L. M., and Lin, S.: How Well Does an FV3-Based Model Predict Precipitation at a Convection-Allowing Resolution? Results From CAPS Forecasts for the 2018 NOAA Hazardous Weather Test Bed With Different Physics Combinations, Geophys. Res. Lett., 46, 3523-3531, https://doi.org/10.1029/2018GL081702, 2019.

Zhang, X., Kondragunta, S., Da Silva, A., Lu, S., Ding, H., Li, F., and Zhu, Y.: The Blended Global Biomass Burning Emissions Product from MODIS and VIIRS Observations (GBBEPx), available at: https://www.ospo.noaa.gov/Products/land/gbbepx/ docs/GBBEPx_ATBD.pdf (last access: 28 June 2020), 2019.
Zhang, Y., Liu, P., Pun, B., and Seigneur, C.: A comprehensive performance evaluation of MM5-CMAQ for the Summer 1999 Southern Oxidants Study episode - Part I: Evaluation protocols, databases, and meteorological predictions, Atmos. Environ., 40, 4825-4838, https://doi.org/10.1016/j.atmosenv.2005.12.043, 2006.

Zhang, Y., Vijayaraghavan, K., Wen, X.-Y., Snell, H. E., and Jacobson, M. Z.: Probing into regional ozone and particulate matter pollution in the United States: 1. A 1 year CMAQ simulation and evaluation using surface and satellite data, J. Geophys. Res., 114, D22304, https://doi.org/10.1029/2009JD011898, 2009.

Zhang, Y., Bocquet, M., Mallet, V., Seigneur, C., and Baklanov, A.: Real-time air quality forecasting, part I: History, techniques, and current status, Atmos. Environ., 60, 632-655, https://doi.org/10.1016/j.atmosenv.2012.06.031, 2012a.

Zhang, Y., Bocquet, M., Mallet, V., Seigneur, C., and Baklanov, A.: Real-time air quality forecasting, Part II: State of the science, current research needs, and future prospects, Atmos. Environ., 60, 656-676, https://doi.org/10.1016/j.atmosenv.2012.02.041, 2012b.

Zhang, Y., Hong, C., Yahya, K., Li, Q., Zhang, Q., and He, K.: Comprehensive evaluation of multi-year real-time air quality forecasting using an online-coupled meteorology-chemistry model over southeastern United States, Atmos. Environ., 138, 162-182, https://doi.org/10.1016/j.atmosenv.2016.05.006, 2016.

Zhang, Y., Jena, C., Wang, K., Paton-Walsh, C., Guérette, É.A., Utembe, S., Silver, J. D., and Keywood, and M.: Multiscale Applications of Two Online-Coupled MeteorologyChemistry Models during Recent Field Campaigns in Australia, Part I: Model Description and WRF/Chem-ROMS Evaluation Using Surface and Satellite Data and Sensitivity to Spatial Grid Resolutions, Atmosphere-Basel, 10, 189, https://doi.org/10.3390/atmos10040189, 2019a.

Zhang, Y., Wang, K., Jena, C., Paton-Walsh, C., Guérette, É. A., Utembe, S., Silver, J. D., and Keywood, M.: Multiscale applications of two online-coupled meteorology-chemistry models during recent field campaigns in Australia, Part II: Comparison of WRF/Chem and WRF/Chem-ROMS and impacts of air-sea interactions and boundary conditions, Atmosphere-Basel, 10, 210, https://doi.org/10.3390/ATMOS10040210, 2019b.

Zhou, G., Xu, J., Xie, Y., Chang, L., Gao, W., Gu, Y., and Zhou, J.: Numerical air quality forecasting over eastern China: An operational application of WRF-Chem, Atmos. Environ., 153, 94-108, https://doi.org/10.1016/j.atmosenv.2017.01.020, 2017.

Zhu, Y. and Luo, Y.: Precipitation Calibration Based on the Frequency-Matching Method, Weather Forecast., 30, 11091124, https://doi.org/10.1175/WAF-D-13-00049.1, 2015. 